Louisiana State University

LSU Digital Commons

1965

\title{
Electrode Kinetics at Open Circuit at the Streaming Mercury Electrode.
}

Vakula Sampathkumar Srinivasan

Louisiana State University and Agricultural \& Mechanical College

Follow this and additional works at: https://digitalcommons.Isu.edu/gradschool_disstheses

\section{Recommended Citation}

Srinivasan, Vakula Sampathkumar, "Electrode Kinetics at Open Circuit at the Streaming Mercury Electrode." (1965). LSU Historical Dissertations and Theses. 1056.

https://digitalcommons.Isu.edu/gradschool_disstheses/1056

This Dissertation is brought to you for free and open access by the Graduate School at LSU Digital Commons. It has been accepted for inclusion in LSU Historical Dissertations and Theses by an authorized administrator of LSU Digital Commons. For more information, please contact gradetd@lsu.edu. 
This dissertation has been $\quad 65-11,408$ microfilmed exactly as received

SRINIVASAN, Vakula Sampathkumar, 1936-

ELECTRODE KINETICS AT OPEN CIRCUIT AT THE STREAMING MERCURY ELECTRODE.

Louisiana State University, Ph.D., 1965 Chemistry, physical

University Microfilms, Inc., Ann Arbor, Michigan 
ELECTRODE KINETICS AT OPEN CIRCUIT AT THE STREAMING MERCURY ELECTRODE

\section{A Dissertation}

Submitted to the Graduate Faculty of the Louisiana State University and Agricultural and Mechanical College in partial fulfillment of the requirements for the degree of Doctor of Philosophy

in

The Department of Chemistry

Vakula S. Srinivasan

M.A., University of Madras, India, 1958 May, 1965 


\section{ACKNOWLEDGMENT}

The author expresses his sincere gratitude to Professor Paul Delahay for the suggestion of the problem and continued guidance until it was completed. He also wishes to thank Dr. G. Torsi who collaborated with him in this work, for al* lowing part of his work to be included in the dissertation for its completion. The author would also like to thank all the co-workers in his laboratory, particularly Dr. R. de Levie for enlightened discussions in the course of the work.

Financial assistance from the "Dr. Charles E. Coates Memorial Fund of the L.S.U. Foundation donated by George $H$. Coates" for the publication of the dissertation is gratefully acknowledged. 
TABLE OF CONTENTS

PAGE

ABSTRACT

CHAPTER

I. INTRODUCTION . . . . . . . . . . . . 1

1) The Electrical Double Layer . . . . 1

2) Faradaic Charge Transfer Process. . . 4

3) Combination of Double Layer Charging with Faradaic Proceas . . . . . . 5

4) Previous Work . . . . . . . . . 7

5) Purpose of This Work. . . . . . . 8

II. THEORETICAI ANALYSIS OF THE POTENTIAL OF THE STREAMING MERCURY ELECTRODE. . . . 10

1) General Equation. . . . . . . . . II

2) The Case of Streaming Mercury
Electrode . . . . . . . . . 12

a) Capacity Current . . . . . . . 13

b) Faradaic current . . . . . . . 13

c) The General Case . . . . . . . . 14

d) Mass Transfer Controlled Process . 19

e) Charge Transfer Controlled Process 19

f) Small Overvoltage. . . . . . . . 19

g) Slope-Intercept Analys1s of Data. 20 
III. EXPERIMENTAL METHODS . . . . . . . . 22

1) Solutions . . . . . . . . . 22

2) Apparatus . . . . . . . . 25

a) Cell . . . . . . . . . 25

b) Mercury Jet. . . . . . . . 25

c) Electrometers. . . . . . . . 27

d) Measurements . . . . . . . 27

IV. DESCRIPTION AND DISCUSSION OF RESULTS 30

1) Capacity Current. . . . . . . 30

2) General Case: Mixed Control by Mass Transfer and Charge Transfer. . . 33

a) Large Overvoltage. . . . . . 35

b) Small Overvoltage. . . . . . 35

c) Slope-Intercept Method ..... 44

3) Mass Transfer Controlled Process. - 49

4) Charge Transfer Controlled Process 57

5) The Streaming Amalgam Electrode . . 59

6) Mass Tranafer Control by Diffusion and Migration......... 67

V. CONCLUSION . . . . . . . . . 74 APPENDIX . . . . . . . . . . 75

SELECTED BIBLIOGRAPHY. . . . . . : 78 VITA ................ 80 


\section{IIST OF TABLES}

TABLE

PAGE

I Mixed Control by Mass Transfer and

Charge Transfer. Venadium Total

Concentration $30.9 \mathrm{mM}$ in $1 \mathrm{M}$ Perchlor $1 \mathrm{c}$

Acid, $V(I I): V(I I I)=1: 1 . . . . .38$

II Mixed Control by Mass Transfer and

Charge Transfer. Vanadium Total

Concentration $30.9 \mathrm{mM}$ in $1 \mathrm{M}$ Perchloric

Acid, $V(I I): V(I I I)=1: 5 . . . . .39$

III Mixed Control by Mass Tranafer and

Charge Transfer. Vanadium Total

Concentration $30.9 \mathrm{mM}$ in $1 \mathrm{M}$ Perchloric

Ao1d, $V(I I): V(I I I)=5: 1 . . . . . .40$

IV Exchange Current Density for Different

Ratios of $V(I I)$ and $V(I I I)$...... $4 I$

V Slope-Intercept Analysis: Tangent Values.

Vanadium Total Concentration $31 \mathrm{mM}$ in $1 \mathrm{M}$

Perchloric Acid, V(II):V(III) $=1: 1 . .45$

VI Slope-Intercept Analysis: Tangent Values.

Vanadium Total Concentration $20.7 \mathrm{mM}$ in

$1 \mathrm{M}$ Perchloric Acid (V(II):V(III) $=1: 146$

VII Slope-Intercept Analys1s: Rate Constants. Vanadium Equimolar Ratio as V(II) and

$V(I I I)$. . . . . . . . . . . 47

VIII (a) Large Overvoltage and Diffusion Control: $\mathrm{Hg}(I)$ in $1 \mathrm{M}$ Perchloric Acid, Capillary Radius $7.5 \times 10^{-3} \mathrm{~cm}$. . . . 50

VIII (b) Iarge Overvoltage and Diffusion Control: $\mathrm{Hg}$ (I) in I M Perchloric Acid, Capiliary Radius $6.25 \times 10^{-3} \mathrm{~cm}$. . . . 51 
TABLE

PAGE

IX Small Overvoltage and Diffusion Control

$\mathrm{Hg}$ (I) in $1 \mathrm{M}$ Perchloric Acid, Capillary

Radius $6.25 \times 10^{-3} \mathrm{~cm} . . . . . . .552$

$\mathrm{X}$ Mercurous Ions in $1 \mathrm{M}$ Perchloric Acid,

Comparison of Data. . . . . . . . 56

XI Charge Transfer Controlled Process:

$\operatorname{Cr}(I I)-\operatorname{Cr}(I I I)$ in $1 \mathrm{M}$ Potassium

Chiortde, Capillary Radius $6.25 \times 10^{-3}$

cm................ 61

XII Streaming Amalgam Electrode: Zinc in

1 M Potassium Chloride, Exchange

Current Density . . . . . . . . 63

XIII Streaming Amalgam Electrode: Zinc in

1 M Potassium Thiocyanate, Exchange

Current Density... . . . . . . 64

XIV Mixed Mass Transfer Control: $\mathrm{Hg}(I)$ and

$\mathrm{Hg}$ (II) in Sodium Fluoride. . . . . . 71 


\section{LIST OF FIGURES}

1 Equivalent C1roult of the Electrode Solution Interface, during an Electrode Process. $R_{s}$ is the solution resistance, $C_{d}$ the double layer capacity and $\mathrm{z}_{\mathrm{f}}$ is the element corresponding to the faradaic charge transfer process. . . . . . . . . . . . . . 6

2 Plot for Finding $\lambda$ from the Experimentally Determined Argument. . . . . . . . . . . 18

3 Cell and Capillary of the streaming Mercury Electrode. . . . . . . . . . . . 26

4 Determination of Interfacial Capacity from the Measurement of Capacity Current $1_{\mathrm{c}}$ with the Streaming Mercury Electrode at Different Mass Flow Rates (m) at Fixed Potentials with Respect to the Point of Zero Charge. The numbers on the slopes correspond to $\left(E-E_{Z}\right)$ In volts................. 32

5 Comparison Between the Data Obtained with the Streaming Mercury Electrode and those of Grahame. Grahame's data are shown by the solid lines. . . . . . . . . . . . . 34

6 Plot for Mixed Control, Large Overvoltage$2.58 \mathrm{mM}$ Each of $\mathrm{V}$ (II) and $\mathrm{V}$ (III) in $\mathrm{I} \mathrm{M}$ Perchloric Acld. . . . . . . . . . . 36

7 Determination of Exchange Current Density from the $v \mathrm{vs}$ Plot. Total concentration of vanadium $31 \mathrm{mM}$. Equimolar ratio of $\mathrm{V}$ (II) and V(III) in I M perchlortc acid. . . . . . 42

8 Plot to Determine the Rate Constant and the Transfer Coefficient for V(II) -V(III) Couple in I M Perchloric Acid........... 43

9 Slope-Intercept Analysis - the Ordinate Represents $<\left(g_{m}\right)^{n} / \alpha(f)$. The plots are for equimolar ratio of $V$ (II) and $V$ (III) with $20.7 \mathrm{mM}$ and $31 \mathrm{mM}$ total concentration of $\mathrm{V}$ in $1 \mathrm{M}$ perchloric actd.......... 48 
10 Mass Transfer Controlled Process, Large Overvoltage-Reduction of $\mathrm{Hg}(\mathrm{I})$ in $1 \mathrm{M}$ Perchloric Acid. Two different capillaries were used to verify the relations. Lines $a$ and $b, c$ and $d, e$ and $f$ correspond to $1.03,0.56$ and $0.28 \mathrm{mM} \mathrm{Hg}(I)$, respectively 53

11 Mass Tranfer Controlled Process, Small Overvoltage-Reduction of $\mathrm{Hg}(\mathrm{I})$ in $1 \mathrm{M}$ Perchloric Acid. Lines $a, b$ and $c$ correspond to 10,5 and $2.5 \mathrm{mM} \mathrm{Hg}(\mathrm{I})$, respectively. . . . . . . 54

12 Charge Transfer Controlled Process-Cr(III) $\mathrm{Cr}$ (II) in $1 \mathrm{M}$ Potassium Chloride. Determination of $\alpha$ from the slope. The $\operatorname{Cr}($ III) $-\operatorname{Cr}($ II $)$ ratio is given on the slopes.o and correspond to $0.1,0.04$ and $0.04 \mathrm{M}$ totalCr, respectively. . . . . . . . . . . . . . 58

13 Charge Transfer Controlled Process - Cr(III) Cr(II) in Potassium Chloride. Determination of IO from the slope. The $\operatorname{Cr}($ III) to $\operatorname{Cr}($ II) ratio ig given on the siopes............... 60

14 Plot to Determine the Rate Constant and the Transfer Coefficient for $\mathrm{Zn}(\mathrm{II}) / \mathrm{Zn}(\mathrm{Hg})$ in $1 \mathrm{M}$ Potassium Chloride.............. . 65

15 Plot to Determine the Rate Constant and the Transfer Coefficient for $\mathrm{Zn}(\mathrm{II}) / \mathrm{Zn}(\mathrm{Hg})$ in $1 \mathrm{M}$ Potassium Thiocyanate.

16 Mixed Mass Transfer Control - Reduction of $0.22 \mathrm{mM} \mathrm{Hg}$ (II) in Different Concentrations of Sodium Fluroide as Supporting Electrolyte. $0,0,0$ and $\Delta$ correspond to $0,0.003,0.01$, 0.03 and $0.1 \mathrm{M}$ sodium fluoride, respectively. . 69

17 Mixed Mass Transfer Control - Reduction of $0.21 \mathrm{mM} \mathrm{Hg}$ (I) in Different Concentrations of Sodium Fluoride as Supporting Electrolyte. 0 , and $\Delta$ correspond to $0,0.01$ and $0.05 \mathrm{M}$ sodium fluoride, respectively. . . . . . : 70 


\section{ABSTRACT}

The algebraic sum of the faradalc and double layer charging currents is equal to zero for an electrode of varying area at open circuit. There results a shift of the open circuit potential, and this shift can be correlated to the kinetic parameters for the electrode process. Detalled analysis of this phenomenon has been carried out in this laboratory. Cases of mixed control by mass transfer and charge transfer, control by mass transfer and control by charge transfer were studied with the streaming mercury electrode.

The following systems were-studied: (a) discharge of $\mathrm{Hg}(I)$ in $1 \mathrm{M}$ perchloric acid as example of mass transfer controlled process; (b) the $\operatorname{Cr}(I I I) / \operatorname{Cr}(I I)$ couple in $1 \mathrm{M}$ potassium chloride as a charge transfer

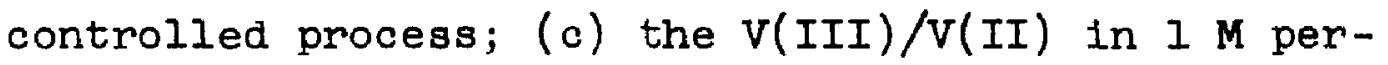
chloric acid and the $\mathrm{Zn}(\mathrm{II}) / \mathrm{Zn}(\mathrm{Hg})$ in $I \mathrm{M}$ potassium chloride and $1 \mathrm{M}$ potassium thiocyanate as processes with mixed control by mass transfer and charge transfer.

The charging current of the streaming mercury electrode was also investigated, and observations were made on the discharge of $\mathrm{Hg}(I)$ and $\mathrm{Hg}$ (II) with mixed control by diffusion and migration. 


\section{CHAPTER I}

\section{INTRODUCTION}

When a quantity of electriclty passes across an electrolyte-metal or a molten salt-metal interface two processes must be considered: (1) the non-faradaic charging of the electrical double layer; and (2) the faradaic charge transfer process corresponding to an electrode reaction, 1.e., a process involving net oxidation or reduction. These two processes will be briefly reviewed.

\section{1) The Electrical Double Layer}

Electrolyte-metal interfaces behave like an electric capacitor but, unlike an electric capacitor, the capacitance of the interface depends upon the electrode potential, as measured against some reference electrodes, and the composition of the solution. Hence the study of the capacity of the interface throws light on the properties of the interface. (See Grahame's review ${ }^{1}$ and Delahay's monograph. ${ }^{2}$ )

$I_{D}$. C. Grahame, "The Electrical Double Layer and the Theory of Electrocapillarity", Chem. Rev., 41, 441 $(1947)$.

${ }^{2}$. Delahay, "Double Layer and Electrode Kinetics", Intersolence-Wiley, New York, in press. 
We consider an ideal polarized mercury electrode in equilibrium with the electrolyte, that is, an electrode in the absence of any electrode reactions. It is evident that the algebratc sum of the charges on either side of the interface is equal to zero. If the charge on the metal side is positive, anions are predominant In the immediate vicinity of the interface, in the solution side and vice versa. Thus a clear charge separation at the interface gives rise to the electrical capacitance-like behavior.

A thermodyanamic approach to correlate the experimentally observed surface properties and the composition of the solution has been made by G. IIppmann as early as 1875. In his famous equation, which Is derivable from Gibbs' adsorption isotherm, the surface tension is related to the charge at the interface and the composition of the solution. Thus, one has at constant temperature and pressure and for a solution of a single electrolyte

$$
-d \gamma=q_{M} d E \pm+\Gamma_{F} d \mu
$$

is the interfacial tension, $q_{m}$ the charge on the electrode, Et the potential with respect to a reference electrode which 18 reversible to the cation or the anton, respectively, $\Gamma_{f}$ is the anton $\left(\Gamma_{-}\right)$or the cation 
$\left(\Gamma_{+}\right)$relative surface excess, and $\mu$ is the electrolyte chemical potential. It follows from the above equation that the charge on the electrode per unit area is given by

$$
q_{n}=-\left(\frac{\partial \gamma}{\partial E}\right)_{\mu}
$$

at constant temperature and pressure, the chemical potentials $\mu$ being kept constant. Equation $1-1$ can be generalized for mixtures of several electrolytes.

Thus, the charge on the electrode $1 \mathrm{~s}$ a thermodynamic quantity which can be determined from the variations of surface tension with $\mathrm{E}$ the potential (electrocapillary curve). The $r$ versus $E$ curve has the shape of a parabola but is not a parabola. The potential for which $\left(\frac{\partial \gamma}{\partial E_{ \pm}}\right)=0$ is the point of zero charge or $\mathrm{E}_{z}$, which is also referred to as electrocapillary maximum (E.C.M.). It is sometimes convenient to express the potential of the electrode with respect to the point of zero charge, and potentials in this scale as referred to as "rational potentials". The sign of the charge on the electrode is that of the rational potential.

The interface capacity can be defined in two ways: (1) by the integral capacity $c_{1}$ according to

$$
q_{m}=c_{1}\left(E-E_{z}\right)
$$


or (2) by the differential capacity $c_{d}$ according to

$$
c_{d}=\left(\frac{d q m}{d E}\right)_{p, r, \mu}
$$

One has

$$
q_{m}=\int_{E_{z}}^{E} c_{d} d E
$$

2) Faradaic Charge-Transfer Processes

We consider a simple electrode reaction with a single rate determining step corresponding to the equation

$$
0+n e=R
$$

where both the components are soluble in the electrolyte and/or electrode. In the absence of complications due to mass transfer or a coupled chemlcal reaction, the current density-potential variations for reaction 1-6 are accounted for by the equation

$$
I=I_{a}^{*}\left[\exp \left(-\frac{\alpha \eta F}{R T} \eta\right)-\exp \left((1-\alpha) \frac{n F}{R T} \eta\right)\right]
$$

where $I_{a}^{O}$, the apparent exchange current density and $\alpha$, the transfer coefflcient, are the parameters characterizing the reaction kinetics. The overvoltage $\eta$ is equal to $\left(E-E_{e}\right)$, the difference between the electrode potential $E$ at the current density $I$ and the equilibrium potential $E_{e}$ at $I=0 . R, T, F$, have their usual physical chemistry meaning. Equation $1-7$ is 
written for the convention according to which a net reduction (cathodic) current is positive and net oxidation (anodic) current is negative.

If the concentrations of $O$ and $R$ at the electrode surface $C_{O}$ and $C_{R}$ are different from the concentrations in the bulk of the solution $C_{0}^{O}$ and $C_{R}^{O}$, mass transfer polarisation should be considered. Then equation 1-7 becomes

$$
I=I_{a}^{*}\left\{\frac{c_{0}}{c_{0}} \exp \left[-\frac{\alpha \pi F}{R T} \eta\right]-\frac{c_{\pi}}{c_{R}} \exp \left[(1-\alpha) \frac{n F}{R T} \eta\right]\right\}
$$

3) Combination of Double Layer Charging with Faradaic Charge Transfer

A simple way of representing both the transfer processes is given Fig. I from which it is seen that the charge-transfer process corresponds in effect to "leakage" of the double layer capacity.

The presence of a non-faradaic process limits the sensitivity of most existing electro-analytical techniques based on measurement of a faradalc current. However, in the recently developed collostatic method 3,4 the potential of the electrode is changed in a very short time (microsecond-duration) and the subsequent variations

3P. Delahay, "Fundamentals of Coulostatic Analysis", Anal. Ghem., 34, 1267 (1962).

4p. Delahay, "Coulostatic Method for the Kinetic Study of Fast Electrode Processes. I. Theory", J. Phys. Chem., 66, 2204 (1962). 


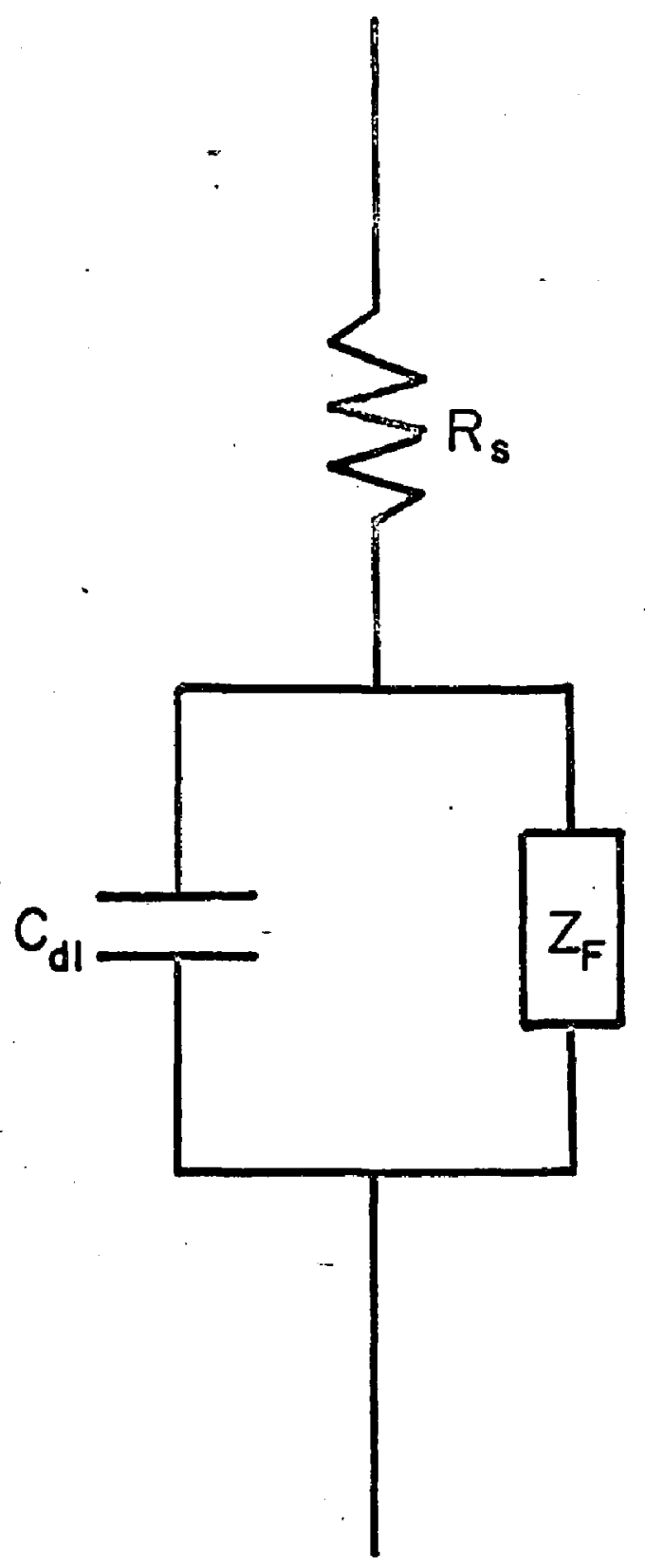

F1g. 1 - Equivalent circuit of the electrode-solution interface, during an electrode process. $R_{s}$ is the solution resistance, $\mathrm{C}_{\mathrm{dl}}$ the doublelayer capacity and $z_{f}$ is the element corresponding to the faradaic charge-transfer process. 
of potential are followed. A logical extension of the same concept leads to the principle of the work reported here. Instead of using an external source of electrical energy, the electrode reaction itself is used to provide the charge for the double layer, and consequently the study of potential shift from the equilibrium value provides information regarding the kinetic parameters.

\section{4). Previous Work}

It was observed by J. E. Rosenberg and G. Stegeman 5 that a jet of streaming mercury electrode develops a potential different from that of a stationary mercury pool in a solution of mercury ions. Though their general observations were correct, they wrongly attributed this effect to the difference in the rates of adsorption of mercury ions on the stationary electrode and the streaming mercury electrode. Schofield 6 . In his study of expanding mercury electrodes concluded that "on increasing the area of either a flux of electricity must pass across the interface or an equivalent amount of mercurous sulphate must diffuse up to it from the solution (or be produced there by a chemical action) in order to bring equilibrium between the phases."

5J. E. Rosenberg and $\mathrm{G}$. Stegeman, "The Adsorption of Ions by Metallic Mercury", J. Phys. Chem., 30, 1306 (1926).

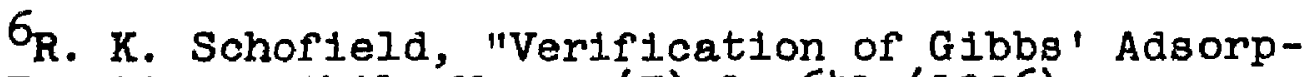
tion Equation", Ph11. Mag., (7) 1, 641 (1926). 
This author arrived at this conclusion while doing experiments to verify Gibbs' adsorption equation.

Watanabe and his coworkers (see review in ref. 7) used a vibrating mercury electrode to measure double layer capacity but they did not consider the possibility of studying electrode kinetics.

Spear 8 studied the variations of potential of a mercury electrode of varying area as resulted from the flow of mercury from a funnel of suitable profile. He considered the 1deal polarized electrode (no faradaic process) and the case of oxygen reduction. The Idea of compensation of the charging current by this faradaic current was clearly stated by Spear. The same idea was independently stated by Delahay 9 and applied to the streaming mercury electrode.

5) Purpose of This Work

The aim of this work is to show how the potential of an electrode of varying area can be explained on the basis of compensation of the double layer charging

7A. Watanabe, "A. C. Methoda in Interfacial Electrical Phenomenon", J. Electrochem. Soc., 110, 72 (1963).

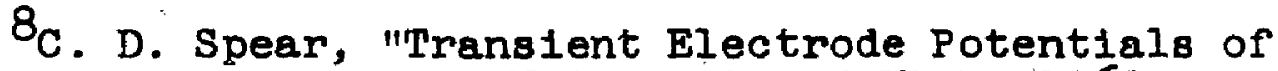
Mercury", dissertation, University of Utah, 1960; microfilms Inc., Ann Arbor, Michigan.

9P. Delahay "Electrode Kinetics at Open Circult at the Streaming Mercury Electrode. I. Theory", J. Electroanal. Chem., in press. 
current by a faradalc current. The study will be made In the particular case of the streaming mercury electrode. The following cases are examined: pure masstransfer control, pure charge transfer control, and mixed control by charge transfer and mass transfer. 
THEORETICAI ANALYSIS OF THE POTENTIAL OF THE STREAMING MERCURY ELECTRODE

The following analysis, according to Delahay ${ }^{1}$, is necessary for the intelligent discussion of experimental results. in subsequent chapters.

Consider an electrode which exhibits the equilibrium potential $\mathrm{E}_{\mathrm{e}}$ corresponding to the charge transfer reaction,

$$
\mathrm{O}+\mathrm{ne}=\mathrm{R}
$$

assuming both $O$ and $R$ are soluble, for given activities of $O$ and $R$. If the area $A$ of electrolyte-electrode interface varies, the double layer capacity which is proportional to area varies. There results a double layer charging current or capacity current which, at open circuit, must be entirely compensated by some faradaic current. If we assume that the above reaction only occurs at the electrode, this reaction proceeds with an overvoltage $\eta$, which can be measured with an Instrument of high input impedance. Hence the current potential characteristics can be determined at open circuit by varying the capacity current density, 1. e. by changing $\left(\frac{1}{A}\right)\left(\frac{d A}{d t}\right)$, where $t$ is the time.

${ }^{1}$ P. Delahay "Electrode Kinetics at Open Circult at the Streaming Mercury Electrode. I. Theory", I. Electroanal. Chem., in press. 


\section{1) General Equation}

The charge $q_{m}$ on the electrode can be written as

$$
a_{m}=c\left(E-E_{z}\right) A
$$

where $c$ is the integral capacity of the double layer expressed for a unit area (heretofore written as $c_{1}$ ), $E$ the potential of the electrode expressed according to the Stockholm I.U.P.A.C. convention, and $E_{z}$ the point of zero charge. If the charge on the electrode varies as the area varies with time by differentiating equation 2-2 with respect to time one gets the capacity current at any instant as

$$
i_{c}=\frac{d q}{d t}=\left(E-E_{2}\right) A\left(\frac{d c}{d t}\right)\left(\frac{d E}{d t}\right)+c A\left(\frac{d E}{d t}\right)+c\left(E-E_{2}\right) \frac{d A}{d t}
$$

If this quantity is positive, a positive charge must be supplied to the electrode, and a net cathodic reaction should occur at the electrode at open circuit. Conversely, a net anodic reaction occurs at open circult when the above quantity is negative. In general, the term in $\left(\frac{d c}{d E}\right)$ is small or negligible and It can be assumed in the analysis of vartous electrodes that $c$ is independent of $E$ in the interval of potential considered. If furthermore conditions are such that

$$
\left|C A\left(\frac{d A}{d t}\right)\right|<\left|C\left(E-E_{2}\right) \frac{d A}{d t}\right|
$$


the net reaction is cathodic or anodic, respectively, according to $c\left(E-E_{z}\right)\left(\frac{d t}{d t}\right) \geq 0$.

Since we adopted, in chapter $I$, for the faradaic current density $I_{f}$ the common convention that $I_{f} \gtrless 0$ for cathodic or anodic process respectively, we write at open circuit

$$
\left(E-E_{2}\right) A\left(\frac{d c}{d t}\right)\left(\frac{d E}{d t}\right)+C A\left(\frac{d E}{d t}\right)+c\left(E-E_{2}\right)\left(\frac{d A}{d t}\right)=T_{f} \quad(2-5)
$$

This equation is valid for any type of electrode.

2) The Gase of the Streaming Mercury Electrode In the study that follows, a streaming mercury electrode of the Heyrovsky ${ }^{2}$ type characterized by a length $I$ and a rate of flow of mercury $m$ is used. The radius $r$ of the mercury column in contact with the solution is assumed to be constant. There is a continual removal of a film of solution with the mercury jet. There results a charging current although the electrode area exposed to the solution is constant.

2J. Heyrovsky and Forjet, "Oszillographische Polarographie", Z. Physik. Chem., 193, 83 (1943). 


\section{a) Capacity Current}

If we consider an elemental area on the streaming electrode, we have

$$
\begin{gathered}
\text { capacity current }= \\
c\left(E-E_{z}\right) \times \text { rate of removal of mercury }
\end{gathered}
$$

$$
\text { Rate of removal }=
$$

Time to travel the length of the column

$$
\text { Area }=2 \pi \mathrm{rI}
$$

$$
\text { Time }=\frac{\text { Length of the fet }}{\text { Velocity of the jet }}=\frac{1}{v}
$$

but the velocity

$$
v=\frac{m}{\pi r^{2} \delta}
$$

where $\delta$ is the density of mercury. Hence,

$$
\text { rate of removal of mercury }=\frac{2 m}{r 8}
$$

and the capacity current is given as

$$
1_{c}=c\left(E-E_{z}\right) \frac{2 m}{r \delta}
$$

Equation 2-12 shows that the capacity current is independent of the length of the jet and depends only on the mass flow rate and the radius of the jet.

b) Faradaic Current

From equation $1-8$ it is possible to write for the faradaic ourrent density 


$$
I_{f}=I_{a}^{u}\left[\left(1-\frac{I_{f}}{I_{c}^{d}}\right) \exp \left[\frac{\alpha n F}{\bar{T} T}\right]-\left(1+\frac{I_{f}}{I_{a}^{\prime}}\right) \exp \left[\frac{(1-\alpha) n F_{\eta}}{R T} \eta\right]\right]
$$

if we substitute for

$$
\frac{C_{0}}{C_{0}^{0}}=1-\frac{I_{f}}{I_{c}^{d}} \quad \text { and } \quad \frac{C_{R}}{C_{k}^{d}}=1+\frac{I_{f}}{I_{d}^{d}}
$$

from Nernst diffusion model. $I_{c}^{d}$ and $I_{a}^{d}$ are the cathodic and anodic diffusion current densitites respectively.

Rearrangement of this equation gives,

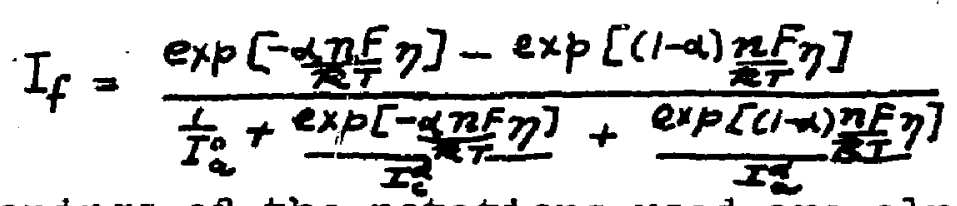

The meanings of the notations used are already explained in the introduction. It is reminded, however, that one has $I_{f} \gtrless 0$ for $\eta \leqslant 0$.

c) The General Case

The current densities $I_{c}^{d}$ and $I_{a}^{d}$ vary along the length of the mercury column. The case of mass transfer by diffusion at the streaming mercury electrode has been treated by Koryta ${ }^{3}$ making the following assumptions :

3J. Koryta, "Diffusion and Kinetic Currents at the Streaming Mercury Electrode", Coll. Czechoslov. Chem. Communs, 19, 433 (1954). 
1) The layer of solution in the immediate vicinity of the electrode is set in motion by the streaming mercury so that it moves at the same speed as mercury.

2) The moving layer is thicker than the diffusion layer.

3) The concentration gradient in the moving layer is perpendicular to the electrode surface. The concentration gradient parallel to the electrode surface is negligible.

4) The diffusion layer is very thin and semiinfinite linear diffusion is the sole mode of mass transfer. -

Koryta obtained for the total current,

$$
i_{d}=4 \pi F \sqrt{\frac{2 l_{m}}{6}} c^{\circ}
$$

The current density $I^{d}$ is

$$
I^{d}=\frac{n F D^{1 / 2} c}{\pi r \delta^{1 / 2}}\left(\frac{m}{l}\right)^{1 / 2}
$$

$m$ denotes the rate of flow of mercury in $\mathrm{gm}^{\mathrm{m}} \mathrm{sec}^{-1}$ and 1 the length of the mercury jet in $\mathrm{cm}$. D expressed in $\mathrm{cm}^{2}$ sec-I is the diffusion coefficient of the substance being reduced or oxldized at the electrode. 8 is the density of mercury flowing.

It can be seen from equations $2-16$ and 2-17 that the faradalc current is directly proportional to $I^{\frac{1}{2}}$ and the faradalc current denstty is inversely proportional to $1^{\frac{1}{2}}$. 
Considering an element of length dl of the mercury jet, from equations $2-15$ and $2-17$ one can write for faradajc current

$$
\begin{aligned}
& d i_{f}=I_{f}^{0} 2 \pi r d l
\end{aligned}
$$

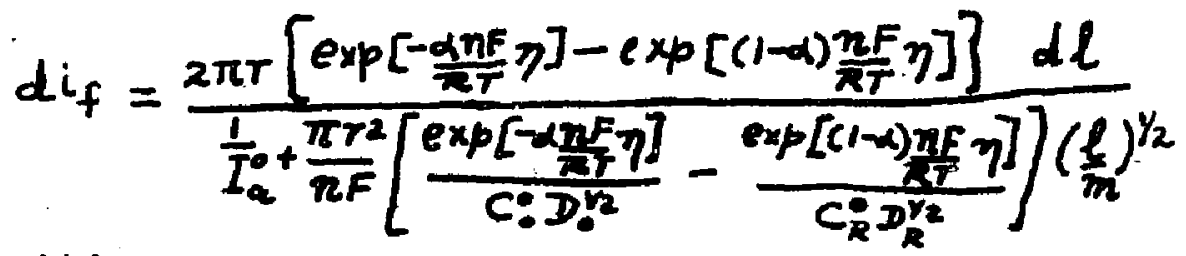

writing

$$
S=2 \pi r\left[\exp \left[-\alpha \frac{n F}{R T} \eta\right]-\exp \left[(1-\alpha) \frac{n F}{R T} \eta\right]\right]
$$

and

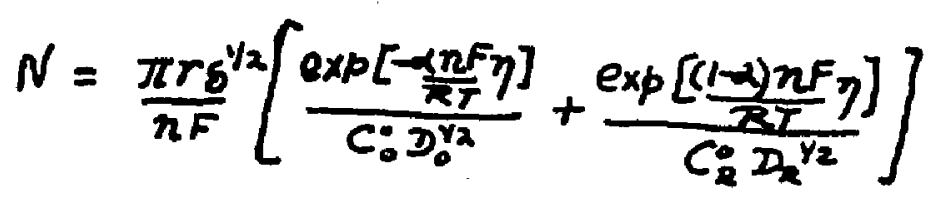

one writes

$$
d i_{f}=\frac{S d \ell}{\frac{I_{a}}{I_{a}}+N\left(\frac{\ell}{m_{m}}\right)^{y_{2}}}
$$

integrating this equation over the limits $1=0$ from the orifice of the capillary to $1=1$, the point at which the solution breaks we get (see appendix 1 )

$$
i_{f}=\frac{25 m}{N^{2}} \frac{1}{\Gamma_{a}^{*}}[\lambda-\ln (1+\lambda)]
$$

where

$$
\lambda=N I_{a}\left(\frac{q}{m}\right)^{1 / 2}
$$


When steady state 1 s reached, equation $2-12$ for the capacity current can be equated to equation 2-22 for farada1c current. Thus

$$
\frac{2 m}{r \delta} c\left(E-E_{2}\right)=\frac{2 S m}{N^{2}} \frac{1}{I_{Q}^{\circ}}[\lambda-\ln (1+\lambda)]
$$

from which one gets (see appendix 2)

$$
G(\eta)=\frac{2 n F r \delta^{1 / 2}}{c}\left(\frac{l}{\pi n}\right)^{1 / 2}\left[1-\frac{1}{\lambda} \ln (1+\lambda)\right]
$$

with

and

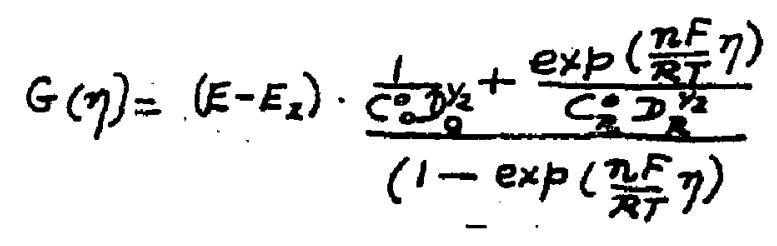

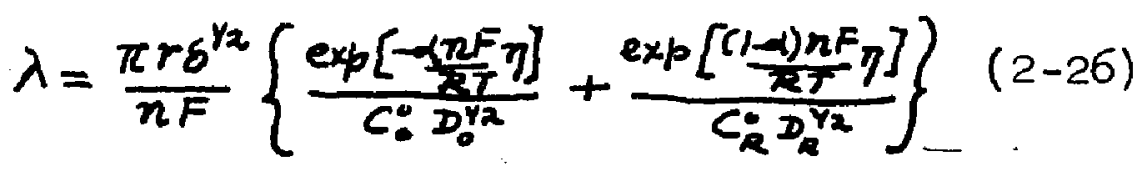

here $c$ is taken at the potential E corresponding to the particular value of $(1 / m)$ at which the electrode operates. It is seen that $G(\eta)$ is proportional to $(1 / m)^{\frac{1}{2}}$ and to the function $\left[1-\frac{1}{\lambda} \ln (1+\lambda)\right]$.

It is possible to write

$$
\begin{aligned}
\left(E-E_{2}\right) & =\left(E-E_{e}\right)+\left(E_{e}-E_{2}\right) \\
& =\eta+\left(E_{e}-E_{2}\right) .
\end{aligned}
$$

hence $G(\eta)$ is an experimental quantity. For each point corresponding to a particular $(1 / \mathrm{m})^{\frac{1}{2}}$ one can calculate the value for the argument in the equation 2-24. A plot relating and $1-1 / \lambda \ln (1+\lambda)$ is made (FIg. 2) from which the corresponding for the calculated argument can be found. 
18

$\because \cdots$

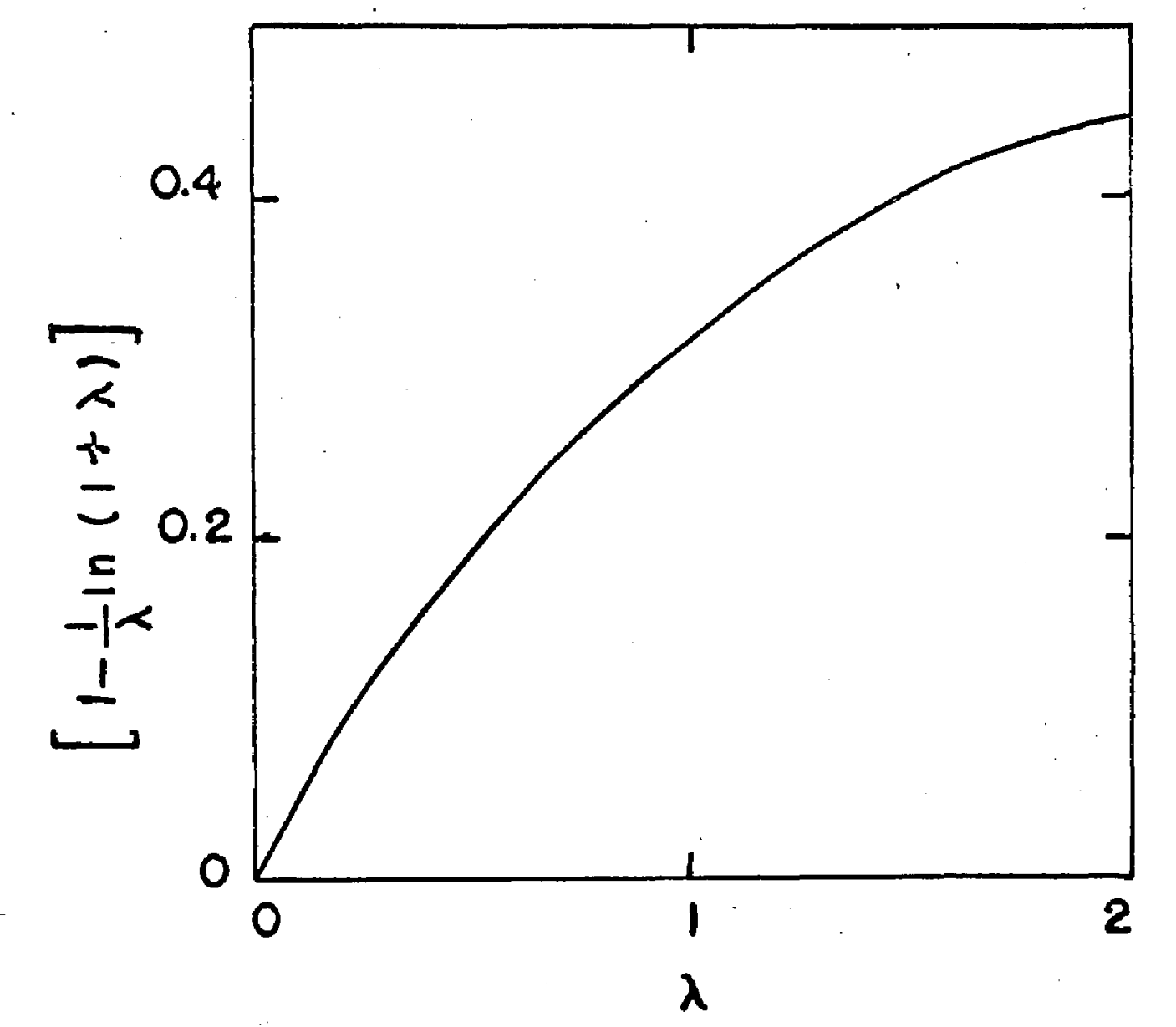

Fig. 2 - Plot for finding $\lambda$ from the experimentally
determined argument. 
Taking the logarithms of both sides of equation 2-26 and rearranging one can write,

$\ln \lambda \cdot \frac{n F}{\pi r \delta^{1 / 2}} \frac{1}{\frac{1}{C_{0}^{0} D_{0}^{y / 2}}+\frac{\exp [n F \eta]}{C_{k}^{t} D F}} \cdot \frac{1}{\left(\frac{2}{m}\right)^{1 / 2}}=\ln I_{-}^{0}-\frac{\alpha n F}{k T} \eta \quad(2-28)$ Hence a plot of experimentally determined quantity on the left handside of equation $2-28$ versus gives the values of $\alpha$ from the slope and $\mathrm{I}_{a}^{O}$ from the intercept.

d) Mass Transfer Controlled Process

For a diffusion controlled process $I_{a}^{O}$ is very high and so $\lambda \rightarrow \infty$ Then argument $1-\frac{1}{\lambda} \ln (1+\lambda) \rightarrow 1$. Instead of $2-24$ we get

$$
G(\eta)=\frac{2 n F r \delta^{1 / 2}}{c}\left(\frac{l}{m}\right)^{1 / 2}
$$

e) Charge Transfer Controlled Process

For a charge transfer controlled process $\mathrm{D} \rightarrow \infty$, so $\lambda \rightarrow 0$. Then $1-\frac{1}{\lambda} \ln (1+\lambda)$ tends towards $\frac{\lambda}{2}$. After proper substitution equation $2-24$ reduces to,

$$
\frac{E-E_{2}}{\exp \left[\frac{-\alpha \pi F}{R T} \eta\right]-\exp \left[\frac{(1-\alpha) n F}{R T} \eta\right]}=\frac{\pi r^{2} \sigma}{c} I_{a}^{0}\left(\frac{l}{m}\right)
$$

f) Small Overvoltage

When is of the order a few millivolts equation 2-24, after expanding the exponentials in $G(\eta)$, neglectIng the second term onwards and rearranging takes the form

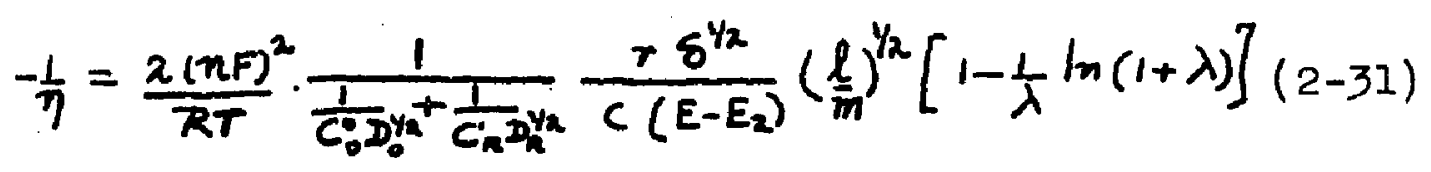


20

with

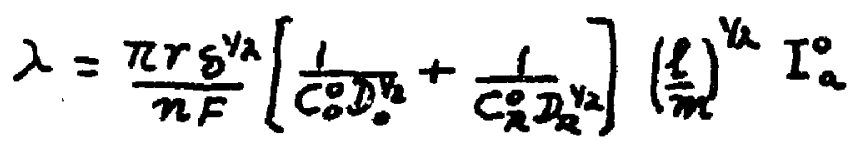

For diffusion control with $\lambda \rightarrow \infty,\left[1-\frac{1}{\lambda} \ln (1+\lambda)\right] \rightarrow 1$, we get

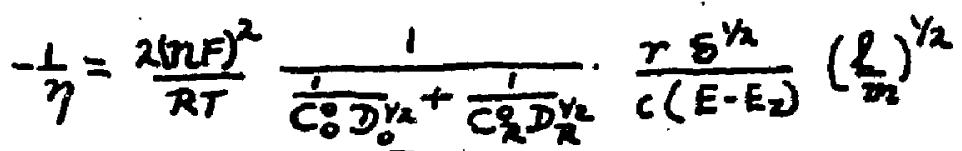

When $\lambda \rightarrow 0$, for pure charge transfer control, the same equation assumes the form,

$$
-\frac{1}{\eta}=\frac{n F}{R T} \frac{\pi r^{2} \delta}{c\left(E-E_{2}\right)} I_{a}^{0}\left(\frac{l}{m}\right)
$$

Thus we see that for small overvoltages $(1 / \eta)$ is proportional to $(1 / \mathrm{m})^{\frac{1}{2}}$ for pure diffusion control and to $(1 / \mathrm{m})$ for pure charge transfer control.

g) Slope-Intercept Analysis of Data

It is shown in the Appendix 3 that for small

overvoltages the $(I / m)^{\frac{1}{2}}-(I / \eta)$ relationship can be written as

$$
\frac{d\left(\frac{\ell}{m}\right)^{1 / 2}}{d(1 / \eta)}=-\frac{P}{Q} \frac{c\left(E-E_{2}\right)}{r \delta}\left[1+\frac{1}{P T_{Q}^{0}}(m / 2)^{1 / 2}\right]
$$

where $P=\pi r^{2}\left(\frac{1}{C_{0}^{0} D_{0}^{r_{*}}}+\frac{1}{C_{R}^{*} D_{R}^{r_{2}}}\right)$

$(2-36)$

and $Q=2 \pi r \frac{n F}{\pi T}$

$(2-37)$

It can be seen from the equation 2-35 that a linear plot of the derivation $\mathrm{d}(1 / \mathrm{m})^{\frac{1}{2}} / \mathrm{d}(1 / \eta)$ against $(\mathrm{m} / 1)^{\frac{1}{2}}$ should give

$$
\text { Intercept }=-\frac{\pi T}{2(n F)^{2}}\left[\frac{1}{C_{0}^{0} D_{0}^{2}}+\frac{1}{C_{R}^{0} D_{R}^{1 / 2}}\right] \frac{c\left(E-E_{R}\right)}{r \cdot 5^{1 / 2}}(2-38)
$$


and

$$
\text { Slope }=-\frac{R T}{\pi F} \frac{C\left(E-E_{2}\right)}{2 \pi r^{2} \delta} \frac{1}{I_{2}}
$$

hence

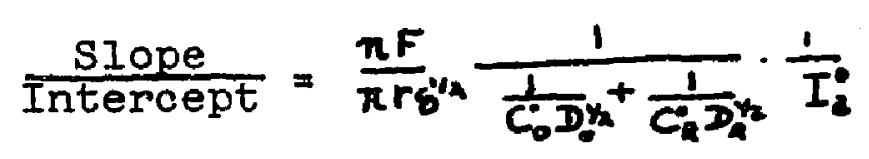

The quantities $c$ and $E_{z}$ need not be known in this method and the analysis is then simplified. 
CHAPTER III

\section{EXPERIMENTAL METHODS}

\section{1) Solutions}

All the chemicals used were of Analytical Reagent Grade. The chemicals were used from freshly opened bottles without any purification. Double distilled water was used in the preparation of all solutions.

A stock solution mercurous nitrate of $0.1 \mathrm{M}$ strength was made in perchloric actd of known strength. The concentration of mercury in the stock solution was determined by electrogravimetry. For experiments described in Section 3, the concentration of mercuric and mercurous nitrate in the stock solutions were of the order of $1 \mathrm{mM}$, to minimise hydrolysis. The mercurous nitrate solution contained $0.001 \mathrm{M}$ perchloric acid. The amount of mercury in these solutions were determined by adding a known excess of standard solution of sodium salt of E.D.T.A. and back titrating the excess with zinc solution of known concentration using Eriochrome Black $T$ as indicator at $\mathrm{pH}$ around 10 .

Approximately a tenth molar solution of vanadyl sulfate was the stock solution of vanadium. Desired concentrations of $\mathrm{V}(\mathrm{II})$ and $\mathrm{V}$ (III) were obtained by 
electrolytically reducing a known emount of vanadyl sulfate in $I \mathrm{M}$ perchloric acid, using a mercury cathode and a platinum anode in an 1solated cell. A potentiostat built in this laboratory was used for electrolysis. Reduction and transfer of solutions were done in an atmosphere of purified nitrogen. The concentrations of $V(I I)$ and $V(I I I)$ were determined polarographically, from the diffusion currents and the capiliary characterlstics.- The diffusion current constant for $V$ (III) was taken as 1.41 from literature. ${ }^{1}$ The stock solution for $\mathrm{Cr}$ (III) was prepared by reducing a known amount of potassium dichromate with hydrogen peroxide and concentrated hydrochloric acid and boiling the solution for two hours to decompose the excess of hydrogen peroxide. For individual experiments, a known amount of this solution was reduced in separatory funnel with zinc amalgam, shaking the solution for two minutes. By this the entire Cr(III) was reduced to $\operatorname{Cr}(I I)$. The amalgam was removed and the solution was transferred to the cell in an atmosphere of pure nitrogen. The desired ratio of $\mathrm{Cr}$ (II) to $\operatorname{Cr}$ (III) was then obtained by controlled aeration.

${ }^{1} \mathrm{~J}$. J. Lingane, "Polarographic Characteristics of Vanadium in Its Various Oxidation States", J. Am. Chem. Soc., 67, 182 (1945). 
The ratio of $\operatorname{Cr}$ (II) to $\mathrm{Cr}$ (III) was monitored with a dropping mercury electrode.

The zinc amalgam for the streaming amalgam electrode was prepared by reducing $250 \mathrm{ml}$ of $20 \mathrm{mM}$ zinc sulfate solution in sulfuric acid on $250 \mathrm{ml}$ of pure mercury. The electrolysis was carried for overnight to remove all the zinc from the solution. A potentiostat was used for high current delivery. Since the electrolysis was carried to completion it was easier to calculate the concentration of the amalgam. ${ }^{2}$ The electrolysis and the transfer of the amalgam were carried in a nitrogen atmosphere. The amalgam in the reservoir was covered with a small amount of dilute sulfuric acid and was kept negatively polarised until actual use. The connecting tube from the reservoir to the capillary was made of "Tefion" to prevent the oxidation of amalgam due to air seepage, usually observed with tygon tubings.

${ }^{2}$. H. Furman and W. C. Cooper, "A Study of the Polarographic Behavior of Amalgem Electrodes", J. Am. Chem. Soc., 72, 5667 (1950). 
2) Apparatus

a) $\mathrm{Cell}$

The cell used (Fig. 3) was a modifled form of the one used by Heyrovsky and Forjet ${ }^{3}$ for the study of the streaming mercury electrode. As the jet carries the solution along with it the level of the solution tends to change continuousiy. To prevent this the side arm of the cell was connected to the main body by a $7 \mathrm{~mm}$.-glass tubing so that the solution finds its level always. The solution in the side arm was held in by tapering the arm to a caplllary and bending it to a reversed $\mathrm{S}$-shape. The mercury collected at the bottom of the bend acted as a seal while permitting at the same time the determination of the mass flow rate of mercury, due to the hydrostatic pressure. There were nitrogen inlets in both parts of the cell. The capillary was introduced from the top of the cell through a stopper.

b) Mercury Jet

The mercury jet was produced by forcing mercury from a reservoir of varying heights, through a precision

3 J. Heyrovicy and Forjet; "Osz11lographische Polarographie", Z. Physik. Chem., 193,.83 (1943). 


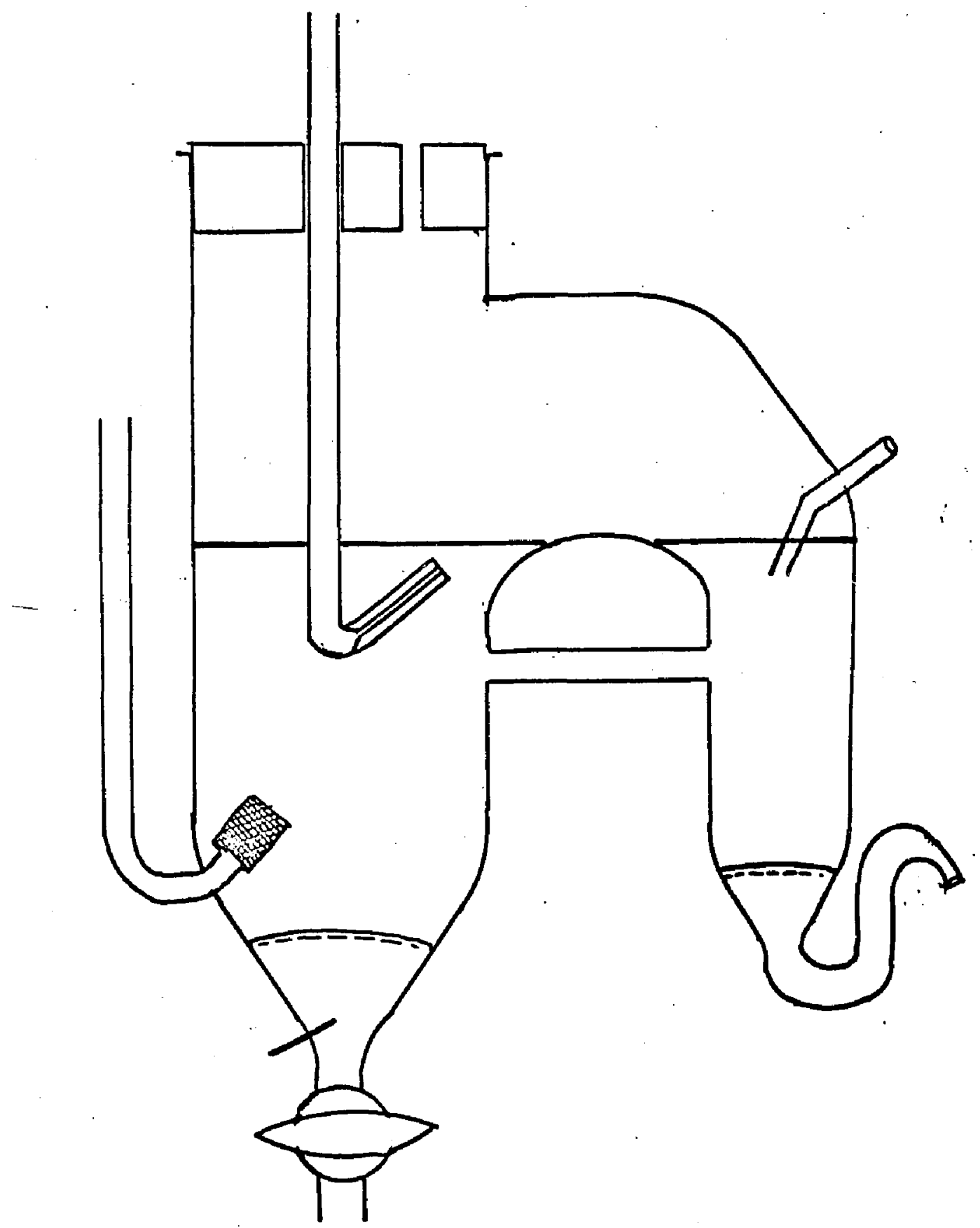

FIg. 3 - Cell and capillary of the streaning mercury electrode. 
bore 4 capillary about $2 \mathrm{~cm}$. Iong attached to a $7 \mathrm{~mm}$ Inner diameter glass tubing. The glass tubing was bent at the bottom approximately $30^{\circ}$ to the vertical, turning upwards.

\section{c) Electrometers}

Hewlett Packard Model 425 A microvolt meter (input impedance 1 megohm), Keithley $600 \mathrm{~A}$ (battery operated, input impedance $10^{14} \mathrm{ohms}$ on the volts position) and Ke1thley 150 A (input impedance 9X $10^{7}$ ohms) electrometers were used for the measurement of overvoltages. Equilibrium potentials were measured. with the usual student potentiometer setup.

\section{d) Measurements}

Though it is uncertain at which point the continuous solution film on the moving mercury jet breaks, it can be assumed that under the experimental conditions the solution film breaks at the cone of the solution level-jet interface. It was verified that the breaking of the mercury jet with a flat glass head up to the immediate vicinity of the solution level had no effect on the meter reading. This cone could be clearly seen

\footnotetext{
${ }^{4}$ Precision bore glass capillaries manufactured by
} Wilmad Glass Co., Inc. Buena, New Jersey. 
when the cell was coated w1th "Desicote", a water repellent coating for glasswares marketed by Beckman, because of the absence of the miniscus. The apparent length of the jet was measured from the tip of the capillary to the apex of the cone with a cathetometer 5 to one tenth of a miliimeter. Care was taken to see that the capillary-support tubing was always vertical, by keeping the horizontal crosswire of the eyeptece in the plane of the solution level and adjusting the glass support to be parallel to the vertical crosswire. The angle of the bend was measured by projecting the capillary on paper. The true length of the fet was calculated from the cosine of the angle.

The capacity data used in this work were taken from the literature and wherever so used proper references are given. However, for $I M$ potassium thiocyanate solution the differential capacity values at various potentials were measured at $1000 \mathrm{~Hz}$ with the impedance bridge bullt in this laboratory. The integral capacities were calculated from the charge obtained by graphical integration using equation $1-5$ for various potentials.

5Made by Griffin George Ltd., London, U. K. 
The electrocaptllary curves were used to determine the point of zero charge. The curves were drawn by measuring the average drop life of twenty drops of a dropping mercury electrode at different potentials in the medium concerned. The electrocapillary maximum was determined in the following manner. The potentials with equal drop time were folned by straight lines. The midpoint of such straight lines were jolned through another straight line and extrapolated to meet the maximum of the curve and the intersection taken as $E_{z}$. All our potentials were referred to this so determined point of zero charge, because the salt-bridge, reference electrode and the arrangements were the same as in the actual study of the electrode process.

In the measurement of the double layer capacity with the streaming mercury electrode in perchloric acid solution, the zero current potential was used as the reference potential $E_{z}$, for this involved no extra experimental measurement.

The Sargent Model XV with I. R. Compensator Model A was used in polarographic analysis.

All experiments were conducted at room temperature, around $24^{\circ} \mathrm{C}$. The maximum variations were less than two degrees. The average temperature was near $27^{\circ} \mathrm{C}$ when studies were made with zinc amalgam. 
CHAPTER IV

DESCRIPTION AND DISCUSSION OF RESULTS

The experimental results are presented along with the discussion. For the convenience of reference some of the equations as derived in chapter II are given along with.

\section{1) Capacity Current}

According to equation 2-12 the capacity current

$$
i_{c}=\left|c\left(E-E_{z}\right) \frac{2 m}{r \delta}\right|
$$

The initial experiments were conducted to verify this equation. The capacity current should be independent of the length of the mercury jet, and it should be possible to determine the integral capacity from capacity current measurements. Perchloric acld solutions of strength $I M$ and $0.01 M$ were chosen so that the capacities so determined could be compared with those reported by Grahame ${ }^{l}$ by his a.c. method. Normal polarographic runs were made with a recorder. The capactty currents for the streaming mercury electrode were recorded for different mass flow rates

${ }^{1}$ D. C. Grahame, "The Electrical Double Layer and the Theory of Electrocapiliarity", Chem. Rev., 41, 441 (1947). 
of mercury in perchloric acid solutions. When the length of the jet was about $1 \mathrm{~mm}$ discontinutty was observed sometimes in the 1-E curves near the zero current region. This effect was already observed by Heyrovsky et aI. ${ }^{2}$ and Valenta ${ }^{3}$ who accounted for it by nonwetting of mercury in the absence of a depolariser when the mass flow rate was slow and the length of the fet was short. It was made certain in our experiments that the jet was completely wet as it left the surface of the solution, by keeping the length of the jet more than $3 \mathrm{~mm}$. The discontinuity was not observed then. The length of the jet was varied from $5 \mathrm{~mm}$ to $9 \mathrm{~mm}$ and it was found that the capacity current did not vary appreclably, as should be the case.

From the $1-E$ ourves for various flow rates $m,{ }_{c}$ values were plotted against $m$ for flxed values of $\left(E-E_{z}\right)$. The slope then should correspond to $\frac{2 c\left(E-E_{z}\right)}{r \delta}$. Such plots are shown in Fig. 4 for $0.01 \mathrm{M}$ perchloric acid solution. From the slope and the radius of the capiliary the capacity was calculated for the particular value of $\left(E-E_{z}\right)$.

2J. Heyrovsky, F. Sorm and J. Forjet, "Capacity Phenomena Displayed at Mercury Capillary Electrodes", Coll. Czechosiov. Chem. Communs., 12, 11 (1947).

3 P. Valenta, "Studium der an der Strömenden Quecksilber-Elektrode auftretenden stromdiskontinultit", Coll. Czechoslov. Chem. Communs., 16, 239 (1951). 


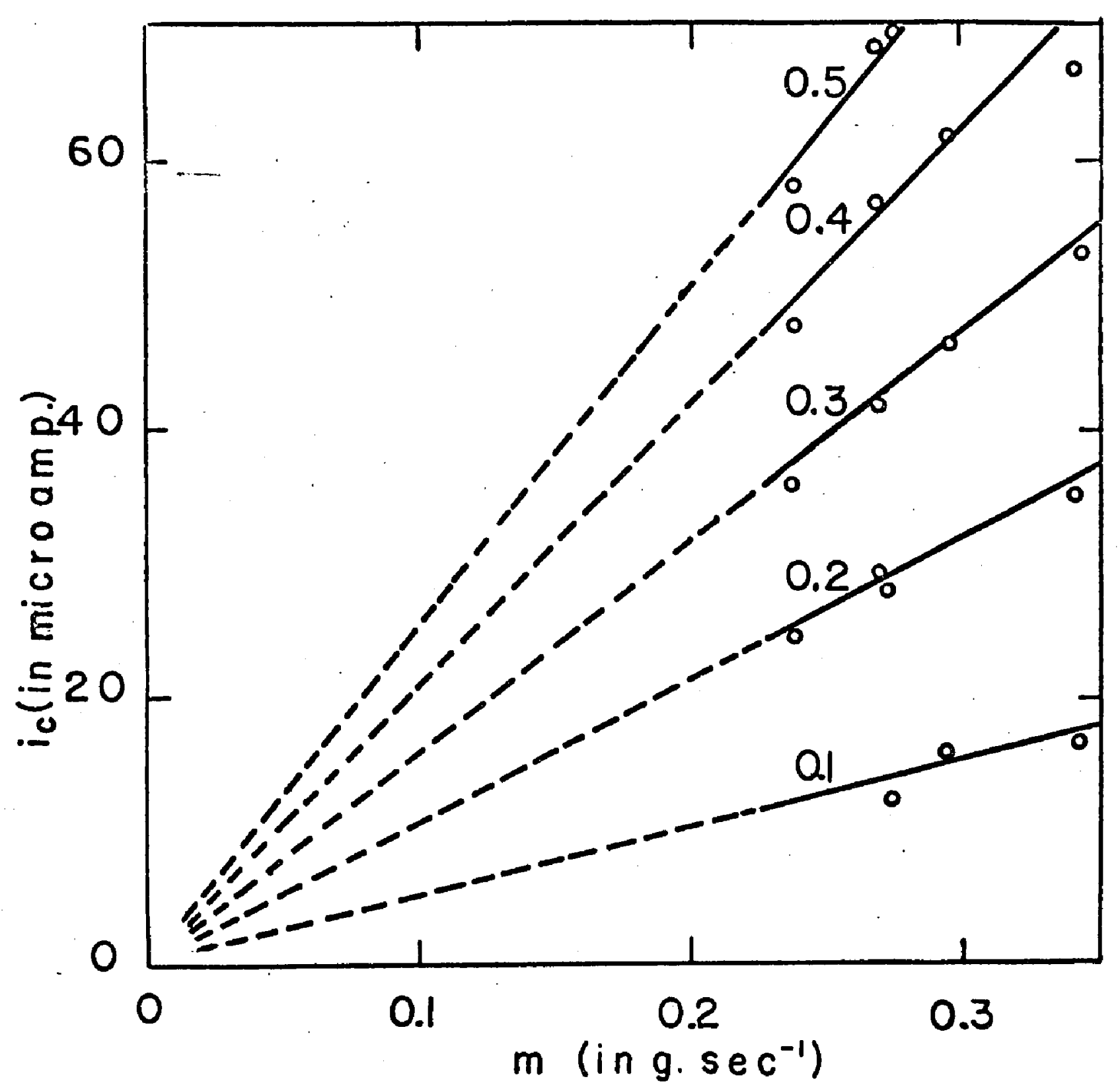

Fig. 4 - Determination of interfactal capacity from the measurement of capacity current ic with the streaming mercury electrode at different mass flow rates $(\mathrm{m})$ at fixed potentials with respect to the point of zero charge. The numbers on the slopes correspond to $\left(\mathrm{E}-\mathrm{E}_{\mathbf{z}}\right)$ in volts. 
Comparison is made in Fig. 5 between the experimentally determined capacity values and the integral capacities obtained from graphical integration of the differential capacities reported by Grahame. The values calculated from Grahame's paper are represented by the solid line.

It appears that there is fairly good agreement on the positive side of the point of zero charge. On the negative side oxygen might be interfering, though the experiments were carried out with deaerated solutions.

2) General Case: Mixed Control by Mass Tranfer and Charge Transfer

$$
V(I I)-V(I I I) \text { couple was chosen for this study. }
$$
This reaction is known to be controlled both by mass transfer and charge transfer. The rate constant is also known from earlier studies with different techniques. The overvoltage in such a system could be varied by changing the total concentration of vanadium and also the ratio of $V(I I)-V(I I I)$. In the later part of this chapter the study with streaming zinc amalgam electrode is reported for the case of small overvoltage only.

The analysis of the general equation $2-24$ is divided into two parts. It simplifies to equation 2-31 for small overvoltages. 


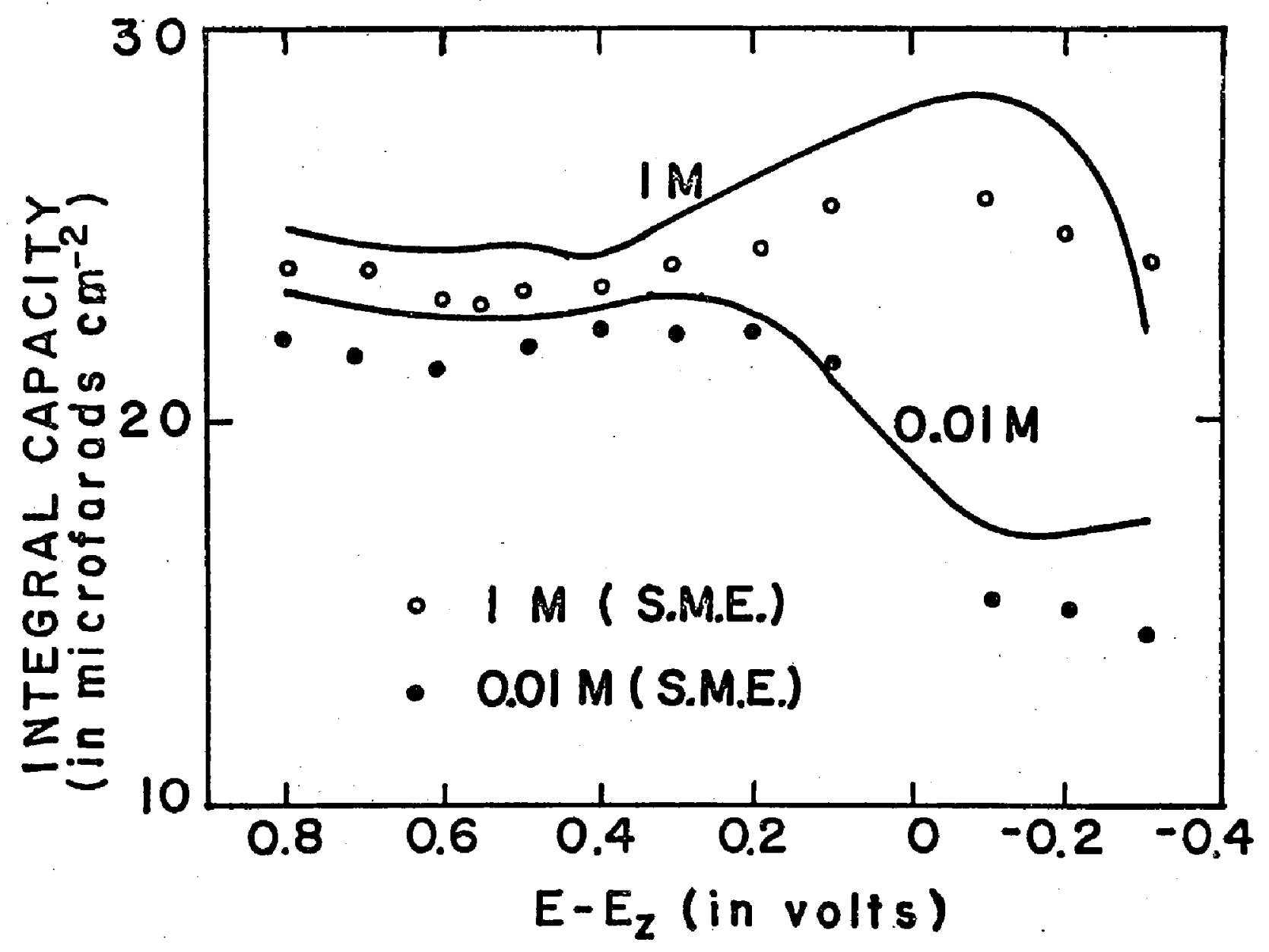

F1g. 5 - Comparison between the data obtained with the streaming mercury electrode and those of Grahame. Grahame's data are shown by the solid continuous lines. 
a) Large Overvoltage

The relationshtp expressed in equation 2-24 was verified for equimolar ratio ( $2.58 \mathrm{mM})$ of $\mathrm{V}(\mathrm{II})$ and $\mathrm{V}$ (III). The overvoltages measured were more than 20 milivolts. In the plot of Fig. 6 the ordinate represents

$$
\log \lambda \frac{n F}{\pi r \delta / 2} \frac{1}{\left(1 / C_{0} D_{0}^{1 / 2}\right)+\left(\exp \left(\frac{n F}{\pi T} \eta\right)\left(\frac{\ell}{m}\right)^{1 / 2} / C_{R}^{0} D_{R}^{\gamma_{2}}\right)}
$$

and the abcissa. The diffusion coefficients for $\mathrm{V}(\mathrm{II})$ and $\mathrm{V}$ (III) were taken as $8.12 \times 10^{-6}$ and $5.38 \times 10^{-6} \mathrm{~cm}^{2} \mathrm{sec} .^{-1}$ respectively. ${ }^{4}$ The radius of the capillary was $6.25 \times 10^{-3} \mathrm{~cm}$. From the intercept $I_{a}^{\circ}$ was calculated. The transfer coefficient was found from the slope. The extrapolation from $20 \mathrm{mv}$ region to the ordinate might be a little presumptuous, but considering the general behaviour of the plot one can see that the equation still holds good. We obtained:

$$
\alpha=0.53 \text { and } k=4.42 \times 10^{-3} \mathrm{~cm} \cdot \mathrm{sec} .^{-1} \text {. }
$$

b) Small Overvoltage

For $\eta \leqslant 5 \mathrm{mv}$ the general equation simplifies to

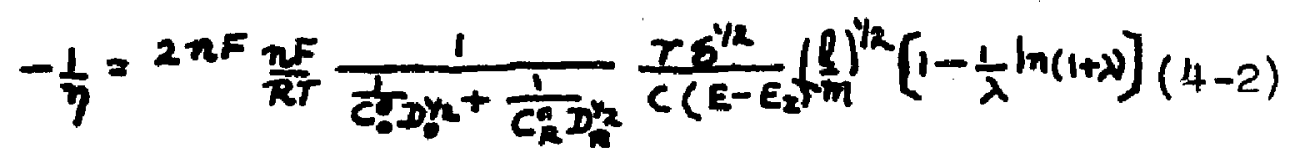

$4 \mathrm{~J}$. Lingane and L. Meites, "Polarographic Characteristics of 2 and 3 Vanadium I. Polarography in Non- complexing Solutions", I. Am. Chem. Soc., 70, 2525 (1948). 


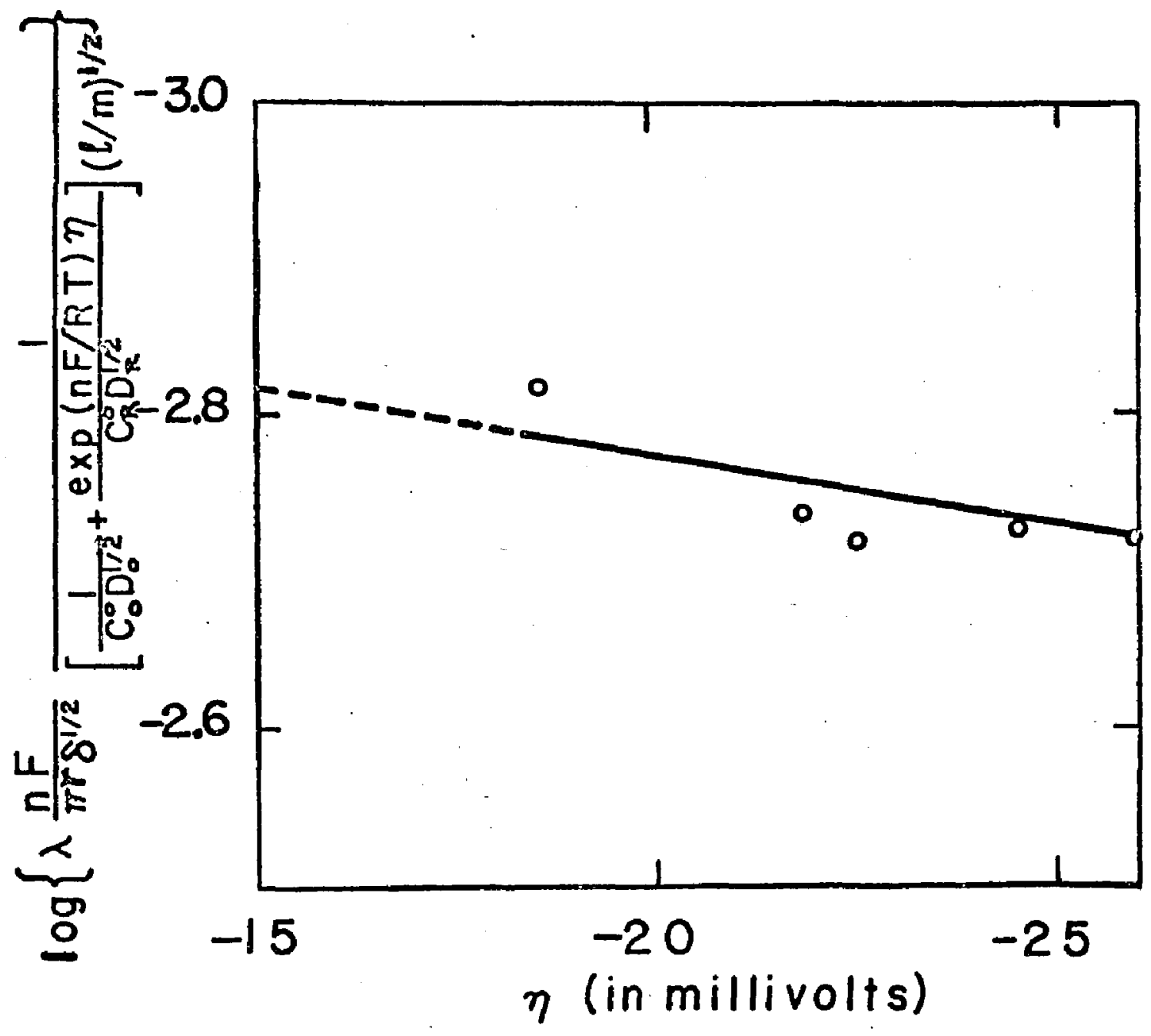

Fig. 6 - Plot for mixed control, large overvoltage. $2.58 \mathrm{mM}$ each of $\mathrm{V}$ (II) and $\mathrm{V}$ (III) in $1 \mathrm{M}$ perchlortc acid. 
and

$$
\lambda=\frac{\pi r s^{1 / 2}}{n F}\left[\frac{1}{C_{0} D_{0}^{y_{2}}}+\frac{1}{C_{R}^{D} y_{R}^{y_{2}}}\right]\left(\frac{l}{m}\right)^{1 / 2} I_{\infty}^{0}
$$

In tables $I$, II, and III the experimental values of $\eta$ for different mass flow rates and the length of the jet are given for the solutions under investigation. As described earlier, the values of $\lambda$ were found by interpolation in the plot in Fig. 2. A plot was made to determine the slope of the $\lambda$ vs. $(1 / \mathrm{m})^{\frac{1}{2}}$ relation from which $I_{Q}^{\circ}$ was calculated. One such plot is shown in Fig. 7 for equimolar ratio of $V(I I)-V(I I I)$. Keeping the total concentration of vanadium constant at $30.9 \mathrm{mM}$, the ratio was varied and the corresponding $I_{a}^{O}$ was calculated. The values of $I_{Q}^{o}$ for different ratios are given in table IV.

Since one has

$$
I_{a}^{0}=n F k C_{0}^{\cdot(1-\alpha)} C_{R}^{* \alpha}
$$

there follows

$$
\log \left(\frac{I_{i}^{*}}{c_{i}}\right)=\log n F k+\alpha \log \left(\frac{c_{k}^{*}}{c_{i}}\right)
$$

A plot of $\log I_{\mathrm{a}}^{\circ}$ va. $\log \left(\mathrm{C}_{\mathrm{R}}^{\circ} / \mathrm{C}_{\mathrm{o}}^{\circ}\right)$ was made (Fig. 8) and from the intercept and the slope $k$ and were calculated. We obtalned the values $k=5.69 \times 10^{-3} \mathrm{~cm}$. $\sec ^{-1}$ and $\alpha=0.56$ which are in fair agreement with 


\section{TABLE I}

Mixed Control by Mass Transfer and Charge Transfer

Vanadium total concentration $30.9 \mathrm{mM}$ in $1 \mathrm{M}$ perchloric actd $\mathrm{V}(\mathrm{II}): \mathrm{V}(\mathrm{III})=1: 1$

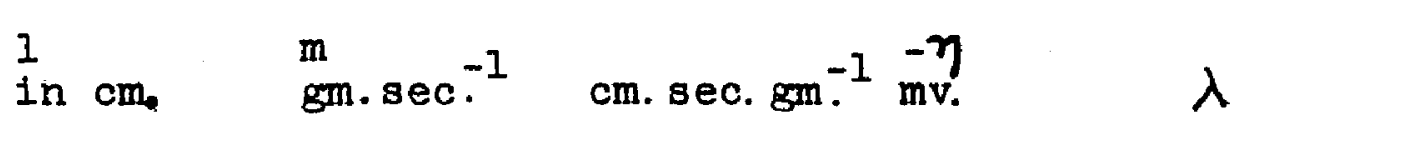

$\begin{array}{lllll}0.696 & 0.255 & 2.73 & 2.45 & 0.53 \\ 0.466 & 0.277 & 1.68 & 3.5 & 0.46 \\ 0.366 & 0.267 & 1.37 & 4.2 & 0.41 \\ 0.388 & 0.306 & 1.27 & 4.5 & 0.39 \\ 0.278 & 0.295 & 0.94 & 6 . & 0.33\end{array}$

$c=25 \mu \mathrm{Fcm}^{-2}\left(\mathrm{E}-\mathrm{E}_{\mathrm{z}}\right): 0.11$ volt $r=6.25 \times 10^{-3} \mathrm{~cm}$. 


\section{TABLE II}

M1xed Control by Mass Transfer and Charge Transfer

Vanadium total concentration $30.9 \mathrm{mM}$ in $1 \mathrm{M}$ perchloric acid VII) : V(III) $=1: 5$

1

$\mathrm{cm}$.

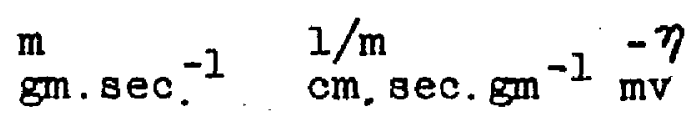

$\lambda$

$\begin{array}{lllll}1.16 & 0.316 & 3.67 & 4.4 & 0.67 \\ 0.887 & 0.289 & 3.07 & 5 . & 0.61 \\ 0.854 & 0.261 & 3.27 & 5.1 & 0.59 \\ 0.748 & 0.261 & 2.87 & 5.8 & 0.54 \\ 0.704 & 0.289 & 2.44 & 6.3 & 0.55\end{array}$

$c=25 \mu \mathrm{F} \cdot \mathrm{cm}^{-2}\left(E-E_{z}\right)=0.16$ volt $r=6.25 \times 10^{-3} \mathrm{~cm}$ 
TABLE III

Mixed Control by Mass Transfer and Charge Transfer

Vanadium total concentration $30.9 \mathrm{mM}$ in $1 \mathrm{M}$ perchloric acId. $V(I I): V(I I I)=5: I$
1
$\mathrm{~cm}$
$\mathrm{m}_{\mathrm{gm}} \mathrm{sec}^{-1}$
$1 / \mathrm{m}$
$\mathrm{cm}$. sec. $\mathrm{gm}^{-1} \mathrm{mv}$

0.629

0.32

1.97

0.78

0.493

0.32

1.54

0.94

0.487

0.32

1.52

1.04

0.388

0.364

1.06

1.2

0.329

0.364

0.903

1.28

0.286

0.364

0.886

1.3

0.275

0.364

0.863

1.4

0.32

0.345

0.721

1.7

$$
r=6.25 \times 10^{-3} \mathrm{~cm} \text {. }
$$

Values are not given because of the high uncertainty involved in the value of $\left(\mathrm{E}-\mathrm{E}_{\mathrm{Z}}\right)$ near the electrocapillary maximum. The slope-intercept method was used to $f$ ind $I_{\mathrm{a}}^{0}$. 
TABLE IV

Exchange Current Density for Different Ratios of V(II) and $\mathrm{V}(I I I)$

\begin{tabular}{ccc}
$\mathrm{C}_{\mathrm{V}(I I I)}^{\circ} \times 10^{6}$ & $\begin{array}{l}\mathrm{C}_{\mathrm{V}(I I) \times 10^{6}}^{\circ} \\
\text { moles ml.1 }\end{array}$ & $\begin{array}{l}I_{\mathrm{a}}^{\circ} \times 1 \mathrm{C}^{3} \\
\text { amp. } \mathrm{cm}^{-2}\end{array}$ \\
\hline 25.9 & 5.16 & 5.33 \\
15.5 & 15.5 & 9.33 \\
5.16 & 25.9 & 6.57 \\
\hline
\end{tabular}




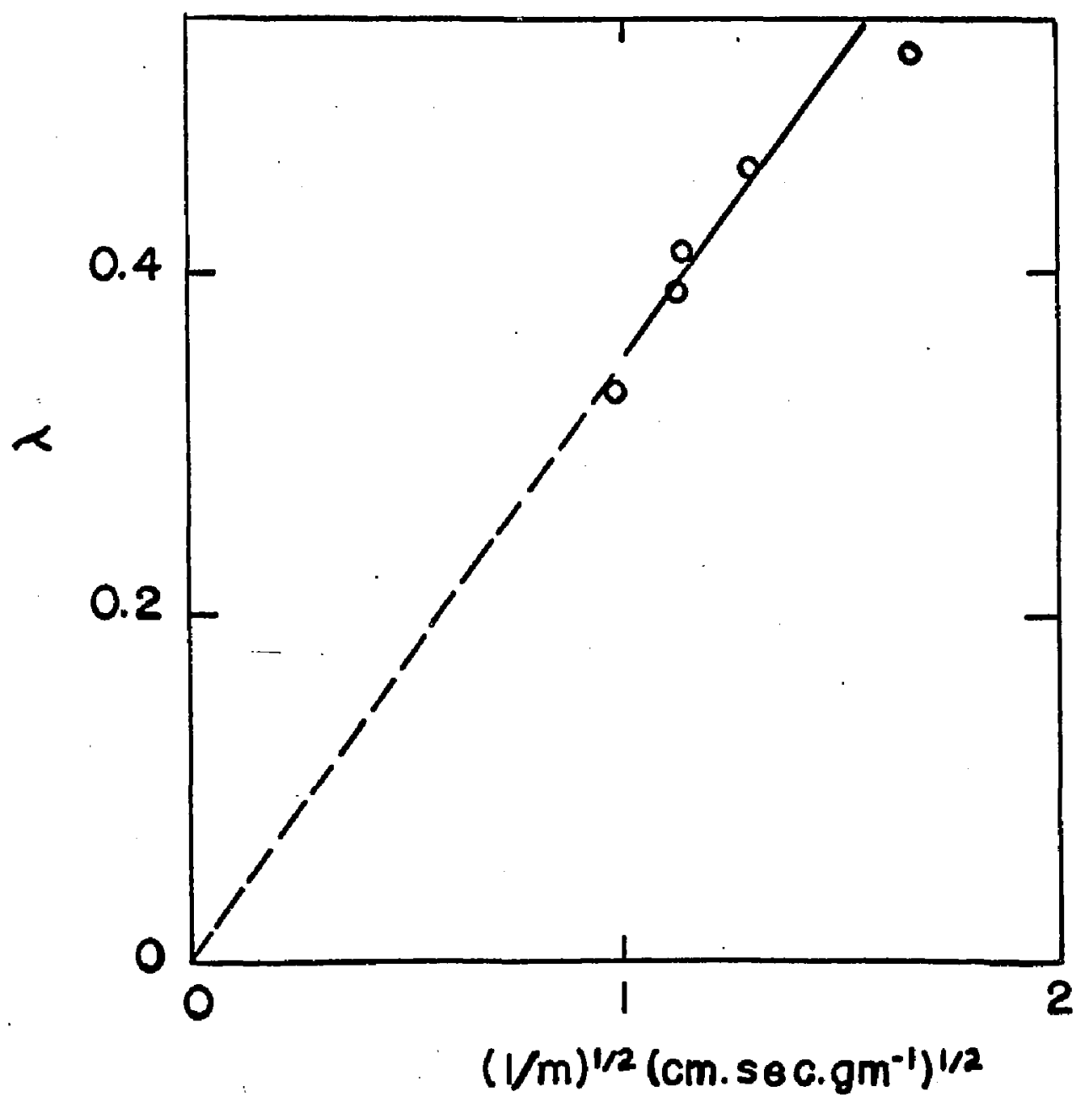

Fig. 7 - Determination of exchange current density from the $\lambda$ vs. $(1 / \mathrm{m})^{\frac{1}{2}}$ plo:. Total concentration of vanadium $31 \mathrm{mM}$. Equimolar ratio of $V(I I)$ and $V$ (III) in $I M$ perchloric acid. 


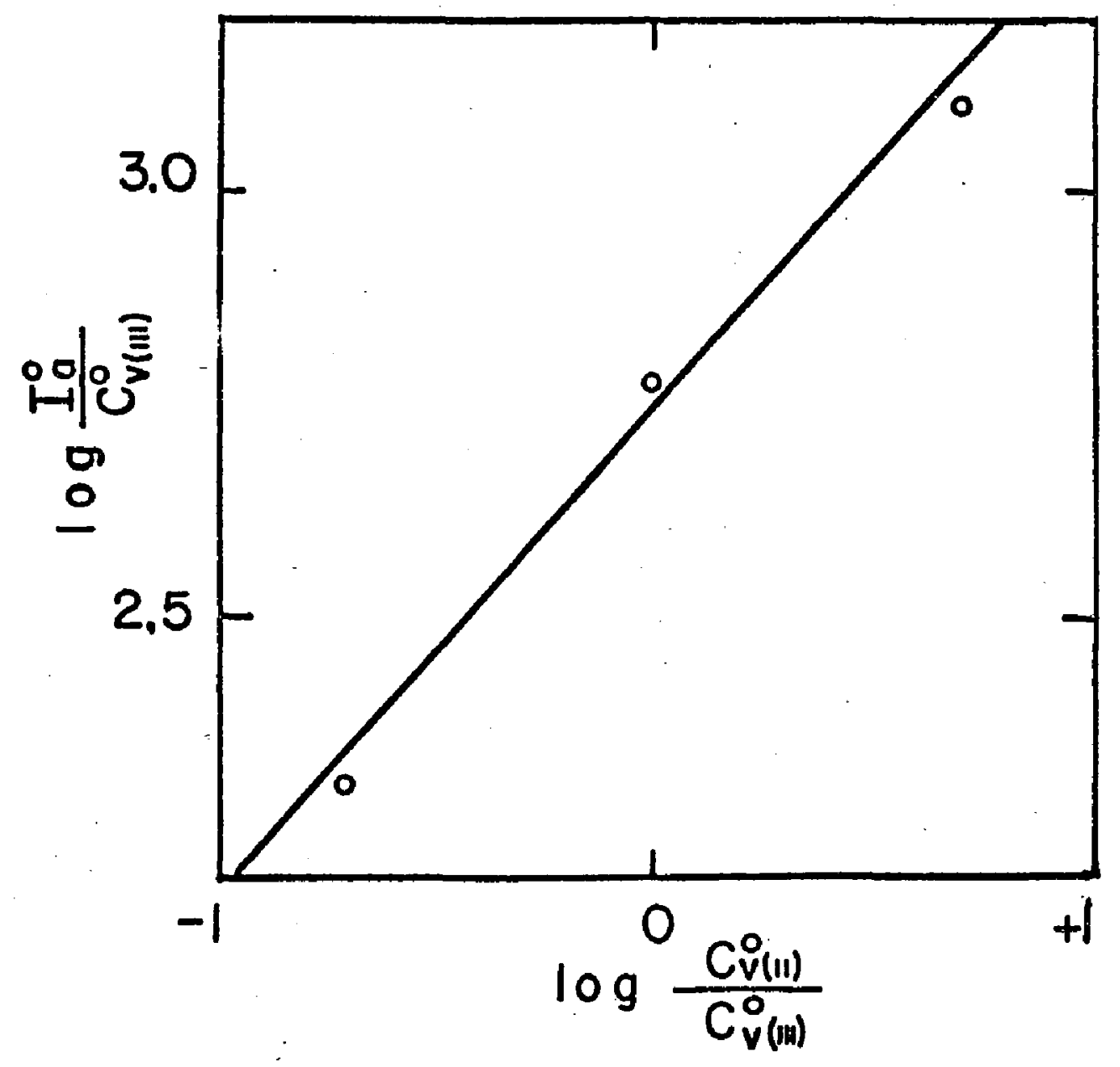

Fig. 8 - Plot to determine the rate constant and the transfer coefficient for V(II) - V(III) couple in $1 \mathrm{M}$ perchloric acid. 
those reported by Randles $5,6\left(\mathrm{k}=4.1 \times 10^{-3} \mathrm{~cm} . \mathrm{sec} .^{-1}\right.$ and $\alpha=0.5-0.57$ ).

c) Siope-Intercept Method

It has been shown in the derivation of equation 2-40 that one can obtain the exchange current density directly from the $1 / \eta$ vs. $(1 / m)^{\frac{1}{2}}$ plot. This method is particularly useful when there is uncertalnty in the value of $\left(E-E_{z}\right)$. A plot was made between $1 / \eta$ and $(1 / m)^{\frac{1}{2}}$ and the curve was differentiated at chosen points.

In the tables $\mathrm{V}$ and VI- the derivatives at the chosen points are given for solutions with $31 \mathrm{mM}$ and $20.5 \mathrm{mM}$ total concentration of vanadium with equal amounts of $V(I I)$ and $V(I I I)$. A plot of the slope was made against $(\mathrm{m} / 1)^{\frac{1}{2}}$ in Fig. 9. Then according to equations 2-39 and 2-40

$$
\begin{aligned}
& \text { Slope }=-\frac{R T}{n F} \frac{c\left(E-E_{z}\right)}{2 \pi r^{2} \delta} \frac{1}{I_{Q}^{0}}
\end{aligned}
$$

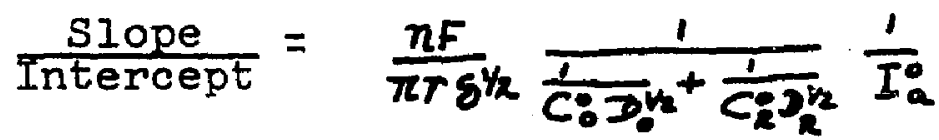

So $I_{a}^{0}$ could be calculated from elther 4-6 or 4-7. The $I_{a}^{0}$ so calculated are given in the table VII.

5J. Randles, "The Determination of Kinetic Parameters of Redox Reactions from Current-Potential Curves", Can. I. Chem., 37, 238 (1959).

$6_{\mathrm{J}}$. Randles and K. Somnerton, "Kinetics of Rapid Electrode Reactions", Trans. Faraday Soc., 48, 937 (1952). 


\section{TABLE V}

\section{Slope-Intercept Analysis: Tangent Values}

Vanadium total concentration $31 \mathrm{mM}$ in I M perchloric
acid $\mathrm{V}(\mathrm{II}): \mathrm{V}(\mathrm{III})=1: 1$
\begin{tabular}{ccc}
$(\mathrm{I} / \mathrm{m})^{\frac{1}{2}}$ & $(\mathrm{~m} / \mathrm{I})^{\frac{1}{2}}$ & $\begin{array}{c}- \text { Tangent } \\
\mathrm{d}(I / \mathrm{m})^{\frac{1}{2}} / \mathrm{d}(1 / \eta)\end{array}$ \\
\hline 1. & 1. & 4. \\
1.1 & 0.91 & 3.61 \\
1.2 & 0.84 & 3.53 \\
1.3 & 0.77 & 3.32 \\
1.4 & 0.72 & 3.16
\end{tabular}




\section{TABIE VI}

\section{Slope-Intercept Analysig: Tangent Values}

Vanadium total concentration $20.7 \mathrm{mM}$ in $1 \mathrm{M}$ perchloric acid $V(I I): V(I I I)=1: 1$

\begin{tabular}{lll}
\hline$(1 / \mathrm{m})^{\frac{1}{2}}$ & $(\mathrm{~m} / \mathrm{l})^{\frac{1}{2}}$ & $\begin{array}{c}- \text { Tangent } \\
\mathrm{d}(1 / \mathrm{m})^{\frac{1}{2}} / \mathrm{d}(1 / \eta)\end{array}$ \\
\hline 1. & 1. & 6.44 \\
1.1 & 0.91 & 6. \\
1.2 & 0.84 & 5.72 \\
1.3 & 0.77 & 5.46 \\
1.4 & 0.72 & 5 \\
\hline
\end{tabular}




\section{TABLE VII}

Slope-Intercept Analysis: Rate Constants

Vanadium equimolar ratio a.s $\mathrm{V}(\mathrm{II})$ and $\mathrm{V}$ (III).

\begin{tabular}{|c|c|c|c|c|}
\hline $\begin{array}{l}\mathrm{C} \text { In } \mathrm{mM} \\
\text { Tot. concr. }\end{array}$ & $\begin{array}{c}\text {-Intercept } \\
\times 10^{3}\end{array}$ & $\begin{array}{r}\text {-slope } \\
\times 10^{3}\end{array}$ & $\begin{array}{l}k_{a}^{\circ} \times 10^{3} \\
\text { from slope }\end{array}$ & $\begin{array}{l}\mathrm{k}_{\mathrm{a}}^{\circ} \times 10 \\
\text { from } \mathrm{sl} \\
\text { interce }\end{array}$ \\
\hline 31. & 1. & 3. & 5.92 & 4.8 \\
\hline 20.7 & 2.25 & 4.2 & 9.53 & 5.12 \\
\hline
\end{tabular}




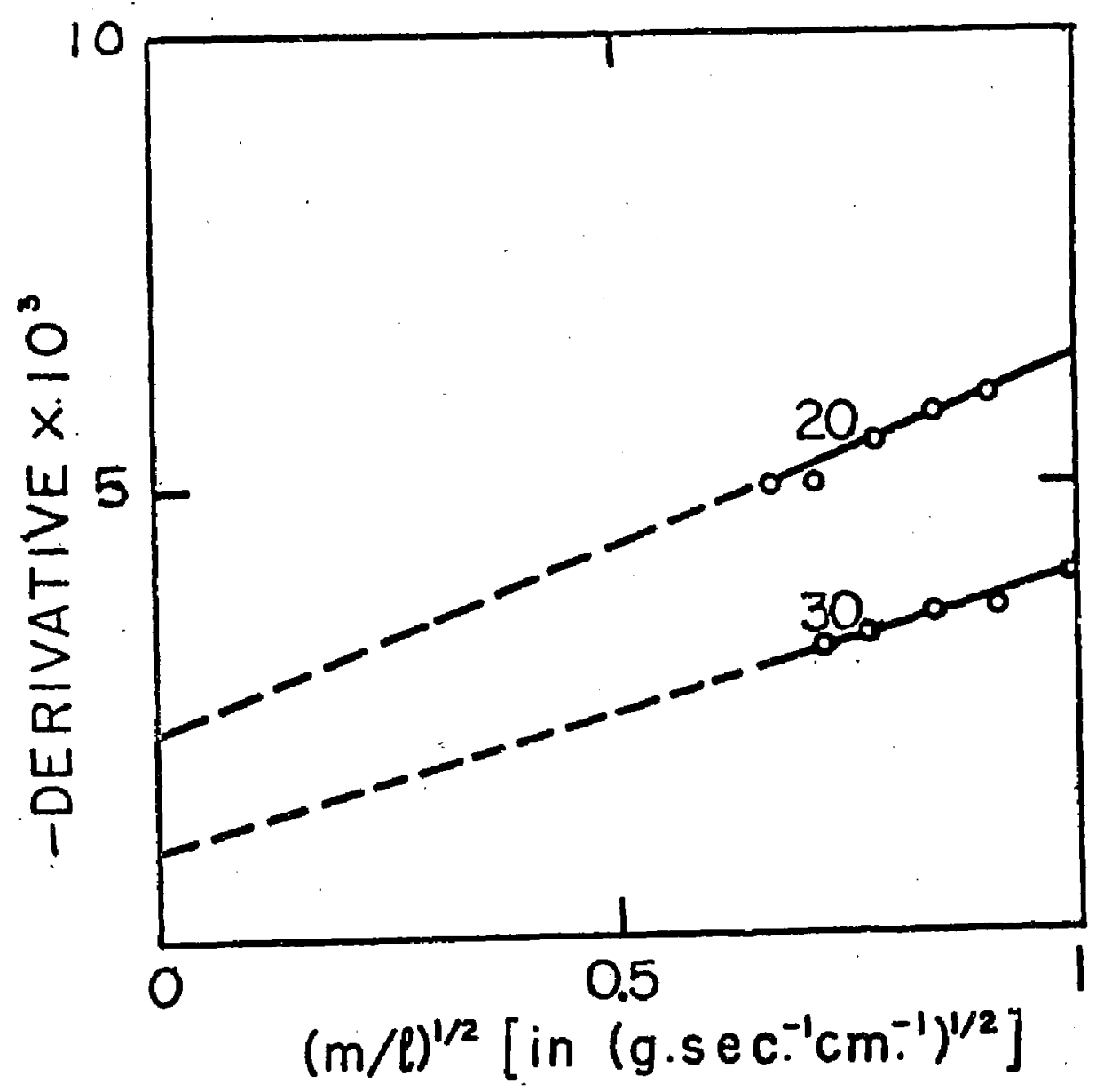

Fig. 9 - Slope-Intercept analysis: The ordinate represents $\alpha(4 / m)$ the piots are for equimolar ratio of $v$ (II) and $V$ (III) with $20.7 \mathrm{mM}$ and $31 \mathrm{mM}$ total concentration of vanadium in $I M$ perchioric aola. 
3) Mass Transfer Controlled Process

For a purely diffusion controlled process, one can assume $I_{a}^{0} \rightarrow \infty$ and hence $\lambda \rightarrow \infty$. So we get

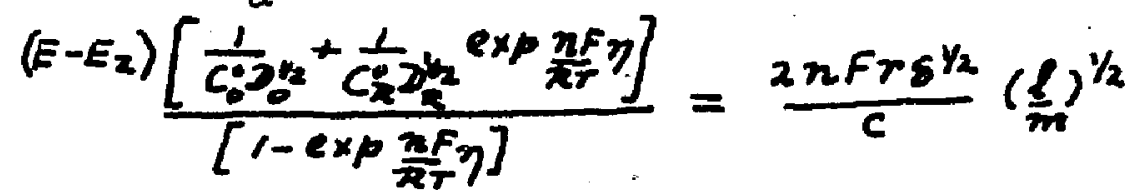

For an electrode reaction involving mercurous ions on mercury electrode the term $1 / C_{R}^{\circ} D_{0}^{\frac{1}{2}}$ is equal to zero. For low overvoltages (less than $5 \mathrm{mv}$ ) the exponent can be approximated by series expansion and taking only the flrst term. Finally by rearrangement we get,

$$
-\frac{1}{\eta}=2 \eta F \frac{\eta F}{R T} \frac{r g^{1 / 2}}{\left(E-E_{2}\right)} \frac{C_{0}^{0} \partial_{0}^{1 / 2}}{C}\left(\frac{l}{\pi}\right)^{1 / 2}
$$

Different concentrations of mercurous ions in $1 \mathrm{M}$ perchloric acid solution as the supporting electrolyte were studied with the streaming mercury electrode. Two different capillaries were used to verify the equations in two independent series of experiments. The data are summarized in tables VIIIa, VIIIb, and IX for both cases, viz. large overvoltage and small overvoltage. In Figs. 10 and $11 \frac{1}{\eta}$ was plotted against $(1 / \mathrm{m})^{\frac{1}{2}}$. From the alope the capacitance of the interface was calculated for that particular potential region and concentration of mercurous lons. It can be seen from the plots that the assumption that the capacitance is fairly constant in the potential region holds well. But the slopes were found not proportional to the concentration 


\section{TABLE VIII(a)}

Large overvoltage and diffusion control : $\mathrm{Hg}(I)$ in $I \mathrm{M}$ perchloric acid. Capillary radius $7.5 \times 10^{-3} \mathrm{~cm}$.

\begin{tabular}{llll}
\hline $\begin{array}{llll}\text { Concn. } \mathrm{Hg}_{2}^{+2} \\
\mathrm{mM}\end{array}$ & $\begin{array}{l}\mathrm{m} \\
\mathrm{gm} . \mathrm{sec} \mathbf{-}^{-1}\end{array}$ & $\begin{array}{l}1 \\
\mathrm{~cm} .\end{array}$ & $\begin{array}{l}\text { overvoltage }-7 \\
\mathrm{mv}\end{array}$ \\
\hline 1.03 & 0.55 & 1.19 & 7.2 \\
1.03 & 0.44 & 1.19 & 5.65 \\
1.03 & 0.4 & 0.72 & 7.45 \\
1.03 & 0.51 & 0.72 & 8.2 \\
1.03 & 0.54 & 0.72 & 9.55 \\
0.52 & 0.37 & 1.08 & 13.3 \\
0.52 & 0.48 & 1.08 & 17.3 \\
0.52 & 0.42 & 0.625 & 26.5 \\
0.52 & 0.48 & 0.625 & 31 \\
0.52 & 0.59 & 0.625 & 58 \\
0.26 & 0.39 & 1.19 & 88 \\
0.26 & 0.49 & 1.19 & 153 \\
9.26 & 0.38 & 0.71 & 298 \\
0.26 & 0.47 & 0.71 & 342 \\
0.26 & 0.60 & 0.75 & 365 \\
\hline
\end{tabular}


TABLE VIII(b)

Large overvoltage and diffusion control: $\mathrm{Hg}$ (II) in $1 \mathrm{M}$ perchlortc acid. Capillary radius $6.25 \times 10^{-3} \mathrm{~cm}$.

\begin{tabular}{llll}
\hline $\begin{array}{lll}\text { Concn. } \mathrm{Hg}_{2}^{+2} \\
\mathrm{mM}\end{array}$ & $\begin{array}{l}\mathrm{m} \\
\mathrm{gm.sec}{ }^{-1}\end{array}$ & $\begin{array}{l}1 \\
\mathrm{~cm} .\end{array}$ & $\begin{array}{l}\text { overvoltage }-\eta \\
\mathrm{mv}\end{array}$ \\
\hline 1.03 & 0.24 & 1.14 & 5.65 \\
1.03 & 0.29 & 1.14 & 6.4 \\
1.03 & 0.24 & 0.55 & 8.95 \\
1.03 & 0.3 & 0.55 & 10.4 \\
0.52 & 0.23 & 1.07 & 12.4 \\
0.52 & 0.29 & 1.07 & 16.0 \\
0.52 & 0.29 & 0.59 & 34.5 \\
0.52 & 0.225 & 0.59 & 23.5 \\
0.26 & 0.26 & 0.95 & 145 \\
0.26 & 0.30 & 0.95 & 190 \\
0.26 & 0.26 & 0.71 & 274 \\
0.26 & 0.28 & 0.71 & 300 \\
& & & \\
\hline
\end{tabular}




\section{TABLE IX}

Small overvoltage and diffusion control: $\mathrm{Hg}(I)$ in I M perchloric acid. Capillary radius $6.25 \times 10^{-3} \mathrm{~cm}$.

\begin{tabular}{|c|c|c|c|}
\hline $\begin{array}{l}\text { Conen. } \mathrm{Hg}_{2}^{+2} \\
\mathrm{mM}\end{array}$ & $\begin{array}{l}\mathrm{m} \\
\mathrm{gm} . \mathrm{sec}^{-1}\end{array}$ & $\begin{array}{l}1 \\
\mathrm{~cm} .\end{array}$ & $\begin{array}{l}\text { overvötage }-\eta \\
\text { mv }\end{array}$ \\
\hline 10.0 & 0.196 & -0.607 & 0.96 \\
\hline 10.0 & 0.188 & 0.463 & 1.1 \\
\hline 10.0 & 0.218 & 0.455 & 1.15 \\
\hline 10.0 & 0.181 & 0.337 & 1.25 \\
\hline 10.0 & 0.198 & 0.342 & 1.51 \\
\hline 5.0 & 0.187 & 0.805 & 1.52 \\
\hline 5.0 & 0.187 & 0.728 & 1.65 \\
\hline 5.0 & 0.219 & 0.629 & 1.91 \\
\hline 5.0 & 0.198 & 0.446 & 2.15 \\
\hline 5.0 & 0.217 & 0.377 & 2.53 \\
\hline 5.0 & 0.199 & 0.321 & 2.56 \\
\hline 5.0 & 0.180 & 0.263 & 2.75 \\
\hline 2.5 & 0.218 & 1.046 & 2.63 \\
\hline 2.5 & 0.214 & 0.77 & 2.93 \\
\hline 2.5 & 0.204 & 0.653 & 3.1 \\
\hline 2.5 & 0.200 & 0.506 & 3.7 \\
\hline 2.5 & 0.210 & 0.452 & 4.07 \\
\hline 2.5 & 0.208 & 0.373 & 4.6 \\
\hline 2.5 & 0.218 & 0.333 & 5.1 \\
\hline
\end{tabular}




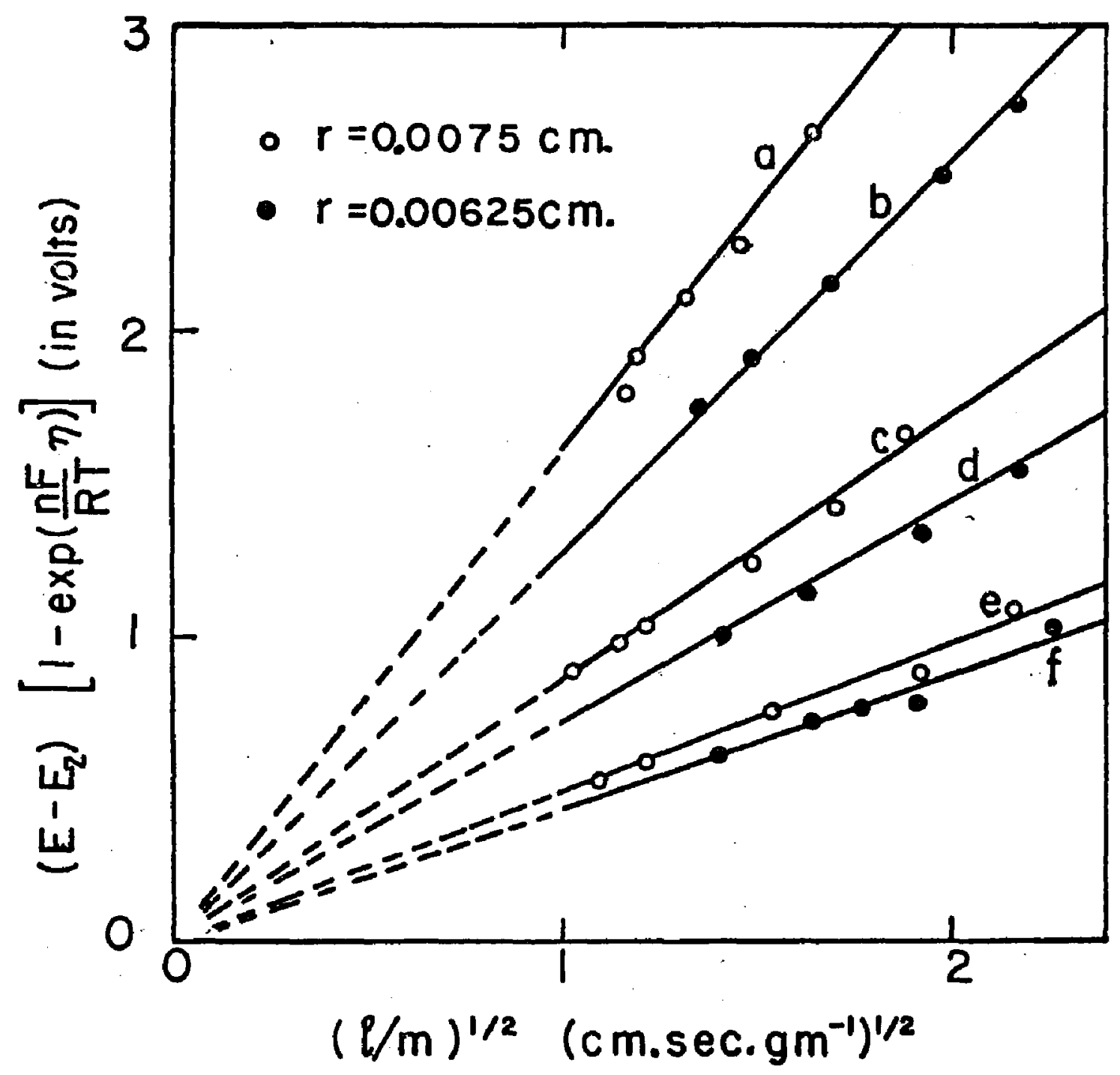

Fig. 10 - Mass transfer controlled process, large overvoltage. Reduction of $\mathrm{Hg}$ (I) in $1 \mathrm{M}$ perchloric acid. Two different capillarles were used to verify the relation. Iines $a$ and $b, c$ and $d$, $e$ and $f$ correspond to $1.03,0.56$ and $0.28 \mathrm{mM}$ $\mathrm{Hg}(\mathrm{I})$, respectively. 


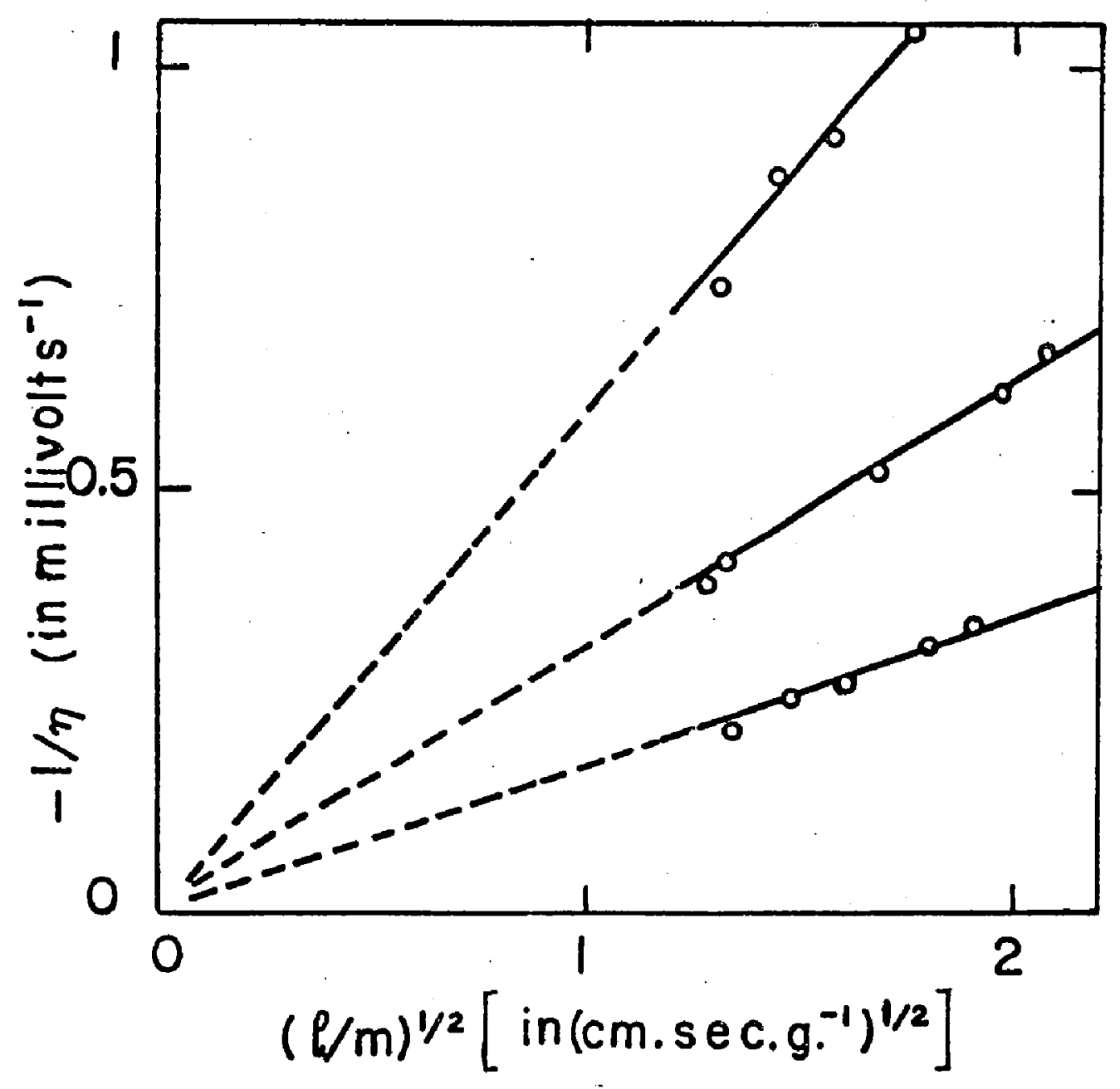

Fig. Il - Mass transfer controlled process, small overvoltage. Reduction of $\mathrm{Hg}(I)$ in $1 \mathrm{M}$ perchloric acid. Lines $a, b$ and $c$ correspond to 10,5 and $2.5 \mathrm{mM}$ of $\mathrm{Hg}(\mathrm{I})$, respectively. 
of mercurous ions, whereas such a proportionality would be expected for a constant capacitance. This might be due to the change in the capacity with the change in mercurous ion concentration.

In table $\mathrm{x}$ the charge on the interface, as calculated from our experiments are compared against those reported by Koenig et al. 7 in their study of mercurysolution interfacial tension at equilibrium potentials. In the last column in the same table, the values obtained from sluyters 18 experiments are given. There seems to be a fair agreement among all these values at more positive potentials. In this region the $\eta$-values are small as the concentration of mercurous ions are high. This region is also the region of dissolution of mercury in Sluyters' experiments. This marked deviation in the capacity values of the interface away from the equilibrium potential might be associated with the effect of electrode process on the capacity of the double layer.

TF. O Koenig, H. C. Wohlers, and D. Bandint, "The Surface Tension between Meroury and Aqueous Solutions of Mercurous Perchlorate and Mercurous Nitrate" paper presented at the Moscow C.I.T.C.E. meeting (1963).

8. Sluyers-Rehbach and J. H. Sluyters, "The Double Layer Capacity of the Mercury-1 $\mathrm{M} \mathrm{HC} 1 \mathrm{O}_{4}$ Solution Interface at High D. C. Potentials", Rec. trav. chim., 83, 217 (1964) 


\section{TABLE $X$}

Compartson of data: Mercurous Ions in $1 \mathrm{M}$ perchloric acid

\begin{tabular}{lcccc}
\hline $\begin{array}{l}\text { Potential } \begin{array}{l}\text { Concentra- } \\
\text { volts }\end{array} \\
\text { tion } \\
\mathrm{mM}\end{array}$ & Ours & Koenig's & $\begin{array}{c}\text { Charge in } \\
\text { coulombs, } \mathrm{cm}^{-2} \\
\text { Sluyters'* }\end{array}$ \\
\hline 1.05 & 10 & 35.3 & 33.4 & - \\
1.04 & 5 & 33.7 & - & - \\
1.03 & $3.16 / 2.5$ & 29.4 & 30.1 & - \\
1.02 & 1 & - & 26 & 27.8 \\
1.01 & 0.32 & - & 21.8 & - \\
0.99 & 0.1 & 17.4 & - & - \\
0.97 & 1 & 20.2 & - & 24.5 \\
0.94 & 0.52 & - & - & 23 \\
& & & & \\
\hline
\end{tabular}

*Sluyters' experiments were done with a bulk concentration of $0.4 \mathrm{mM} \mathrm{Hg}_{2}^{+2}$ in $1 \mathrm{M}$ perchloric actd and the potential was adjusted to the values listed in the first column. 
4) Charge Transfer Process

The $\operatorname{Cr}(I I)$ - $\operatorname{Cr}($ III) reaction in potassium chloride solution is controlled by charge transfer. For such a process equation $2-30$ can be written as

$$
\frac{\left(E-E_{2}\right) \exp \frac{\alpha n F}{\pi T} \eta}{\left(1-\exp \frac{n F}{\pi T} \eta\right.}=\frac{\pi r^{2} G}{c} T_{2}^{0}\left(\frac{l}{m}\right)
$$

Assuming that $I_{Q}^{\circ}$ and are constant for a given ratio of $\mathrm{cr}$ (II) to $\mathrm{cr}$ (III) one can write

$$
\eta=\frac{R T}{\alpha n F} \ln \left\{\frac{\left(1-\exp \frac{n F}{i T} \eta\right)}{\left(E-E_{2}\right)}\left(\frac{l}{\pi}\right)\right\}+\frac{R T}{\alpha \pi F} \ln \left\{\frac{\pi r^{2} \delta I^{\circ}}{C}\right\}
$$

So by plotting $\eta$ against $\log \left\{\frac{\left(1-\exp \frac{n F}{i \eta} \eta\right)}{\left(E-E_{2}\right)}\left(\frac{l}{m}\right)\right\}$ one gets a straight line, from the slope and the intercept of which $I_{a}^{\circ}$ and $\alpha$ can be calculated. The value of capacity $c$ corresponding to the mean $E$ was taken from Parsons' tables. 9 But the small range of potential, the difficulties related to the choice of $\mathrm{E}_{z}$ and other experimental errors did not allow the precise determination of $\alpha$ and $I_{a}^{0}$. A further uncertainty, associated with the determination of $I_{a}^{\circ}$, resulted of the long extrapolation.

To minimize this error, the value of $\alpha$ alone was determined experimentally as shown if Fig. 12 for different ratios of $\operatorname{cr}$ (II) to $\mathrm{Cr}$ (III) and for different

9 Private communication. 


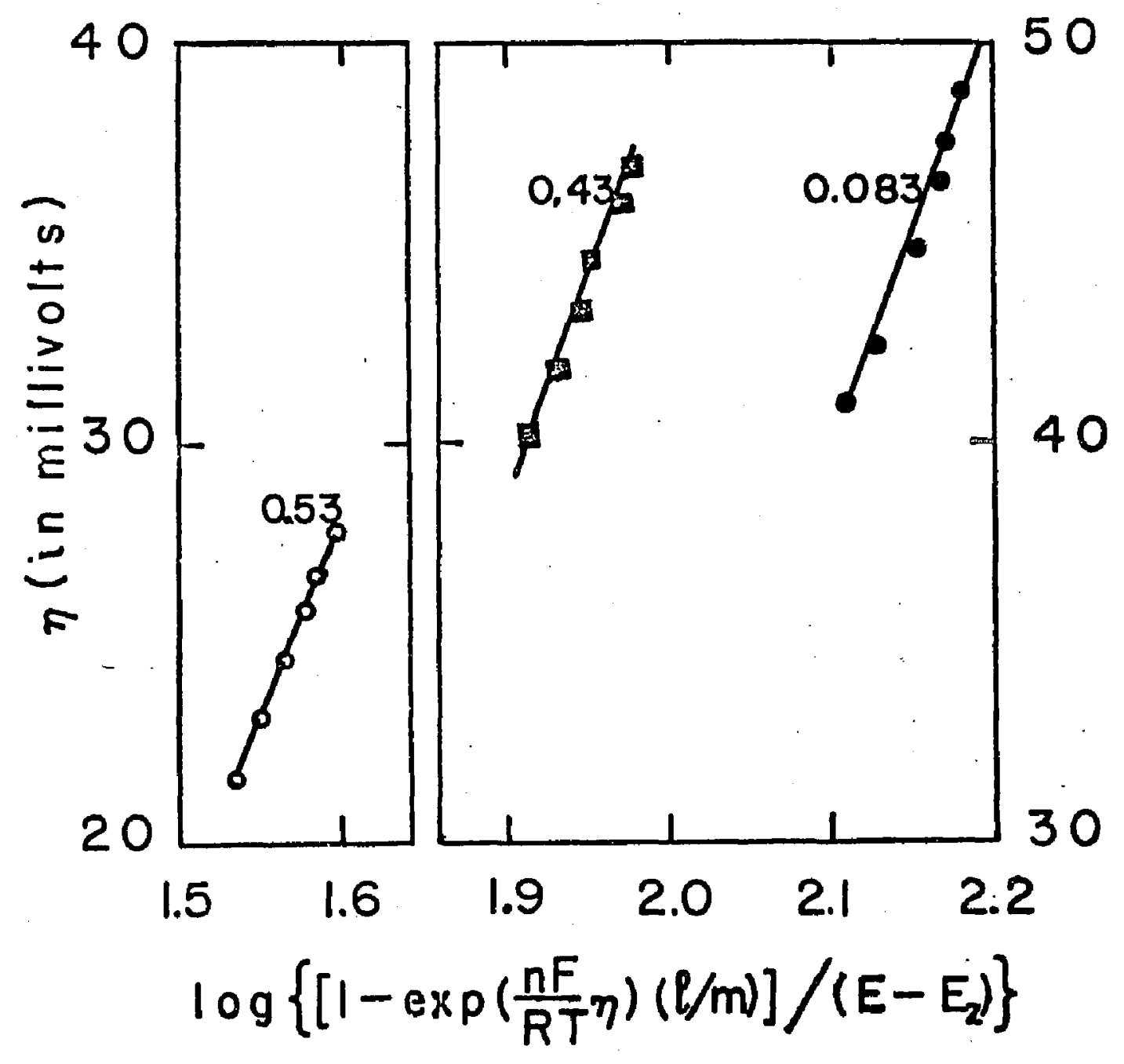

FIg. 12 - Charge transfer controlled process: $\operatorname{Cr}(I I I)-\operatorname{Cr}(I I)$ in $1 \mathrm{M}$ potassium chloride. Determination of $\alpha$ from the slope. The $\operatorname{Cr}($ III) - Cr(II) ratio is given on the slopes.0 and correspond to $0.1,0.04$ and $0.04 \mathrm{M}$ total $\mathrm{Cr}$ respectively. 
total concentrations of $\operatorname{Cr}$ (II) $\operatorname{Cr}($ III). Different values were obtained and the mean value was chosen. With this the left-handside of equation 4-10 was plotted against $(1 / \mathrm{m})$. These plots for some concentrations are shown in Fig. 13. They all pass through the origin as they should. From the slopes values of $I_{Q}^{O}$, and hence of $k_{a}^{\circ}$, were calculated and these are shown in the table XI.

In the literature there is no reference regarding the value of $\alpha$ for this reaction. Randles and Sommerton 6 reported a value $k_{a}^{0}=1.0 \times 10^{-5} \mathrm{~cm} . \mathrm{sec}^{-1}$ which is one order of magnitude smaller than ours.

5) The Streaming Amalgam Electrode

The equations derived in chapter II are equally true for the streaming amalgam electrodes. The validity of the equation for the general case (mixed control) for lower overvoltages was checked for the streaming zinc amalgam electrode in zinc sulphate solutions in $1 \mathrm{M}$ potassium chloride and $I \mathrm{M}$ potassium thiocyenate solutions as supporting electrolyte.

The diffusion coefficient for zinc in zinc amalgam was taken as $16.7 \times 10^{-6} \mathrm{~cm}^{2} \mathrm{sec}^{-1}$ and that of zinc in aqueous solutions as $7.2 \times 10^{-6} \mathrm{~cm}^{2} . \mathrm{sec}^{-1} .10$ The

10N. H. Furman and W: C. Cooper, "A Study of the Polarographic Behaviour of Amalgam Electrodes", J. Am. Chem. Soc., 72, 5667 (1950). 
60

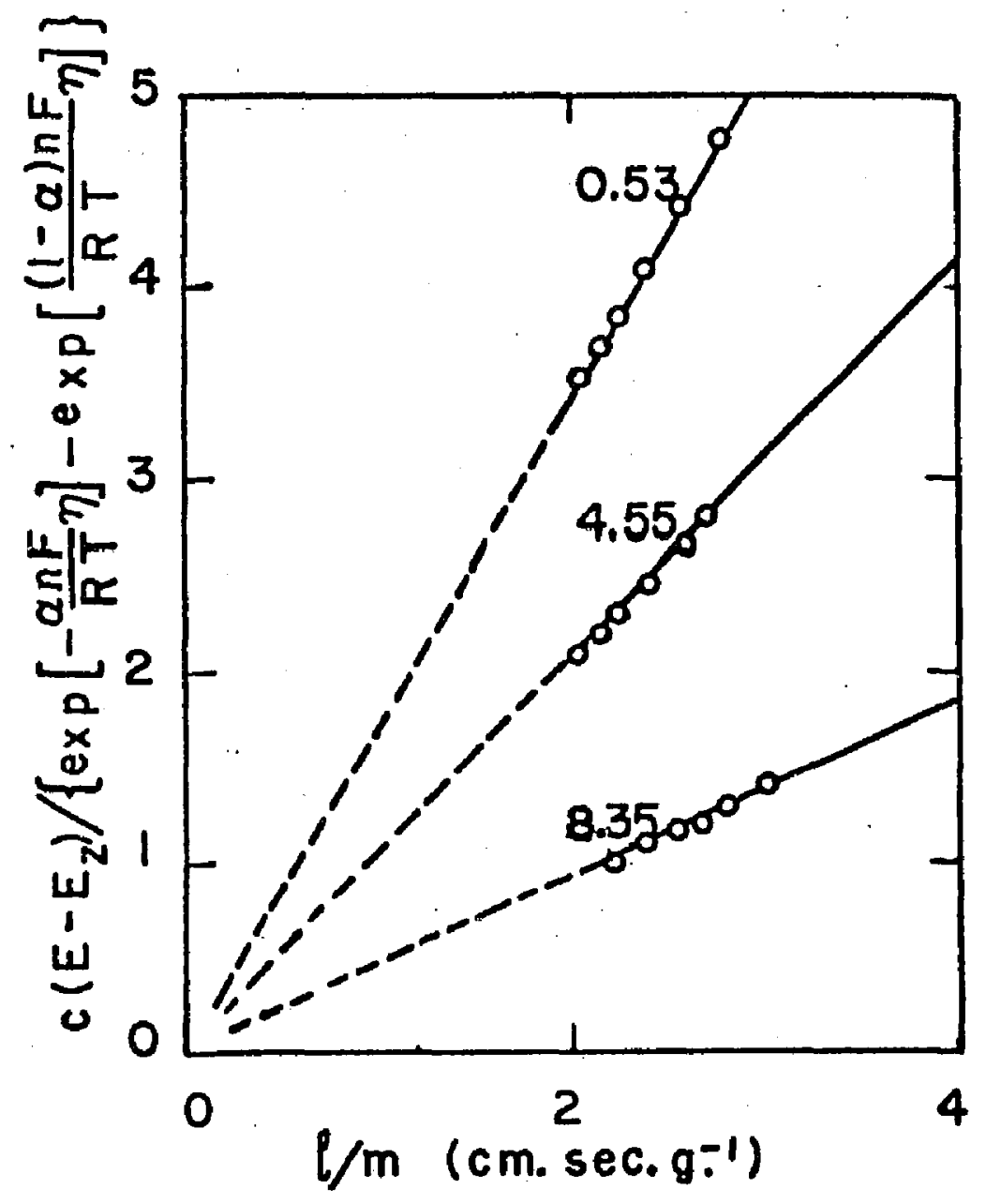

Fig. 13 - Charge transfer controlled process: $\operatorname{Cr}$ (III)$\mathrm{Cr}$ (II) in $1 \mathrm{M}$ potassium chloride. Determination of Io from the slope. The $\operatorname{Cr}($ III ) - Cr(II) ratio is given on the slopes. 


\section{TABLE XI}

Charge transfer controlled process: $\operatorname{Cr}$ (II) to $\operatorname{Cr}$ (III) in $1 \mathrm{M}$ potassium chloride. Capillary radius $7.5 \times 10^{-3} \mathrm{~cm}$.

\begin{tabular}{llll}
\hline $\begin{array}{l}\text { Total Concn. } \\
\text { moles/liter }\end{array}$ & $\frac{\mathrm{cr}+2}{\mathrm{cr}+3}$ & $\begin{array}{l}\alpha \\
\text { by } \\
\text { plot }\end{array}$ & $\begin{array}{l}\mathrm{k}_{\mathrm{a}}^{0} \times 10^{4} \\
\mathrm{~cm} . \mathrm{sec}^{-1}\end{array}$ \\
\hline 0.1 & 4.5 & 0.5 & 0.95 \\
0.1 & 1.9 & 0.64 & 1.4 \\
0.1 & 0.31 & 0.78 & 2.2 \\
0.1 & 0.22 & 0.5 & 1.6 \\
0.1 & 0.17 & 0.78 & 1.8 \\
0.04 & 12 & 0.59 & 2.1 \\
0.04 & 4.2 & 0.54 & 1.7 \\
0.04 & 2.3 & 0.57 & 1.8 \\
0.04 & 1.3 & 0.58 & 1.7 \\
0.04 & 0.77 & 0.51 & 1.9 \\
0.04 & 0.49 & 0.6 & 2.2 \\
0.04 & 0.28 & 0.66 & 2.0 \\
0.04 & 0.12 & 0.79 & 2.3 \\
& 12 & & \\
\hline
\end{tabular}


differential capacity data for $\mathrm{KCl}$ medium was taken from Parson's work. 9 Those for kCNS medium were experimentaliy obtained by the author by the bridge method.

As before, the different methods of analysis for lower overvoltages were carried out for three different concentrations of zinc in each medium. The data are summarized in tables XII and XIII. The rate constant $k$ and the transfer coefficient $\alpha$ were determined by the $\log \left(\frac{T_{0}^{0}}{C_{0}^{0}}\right)$ plot against $\log \left(\frac{C_{R}}{C_{0}^{R}}\right)$. The plota are shown in Figs. 14 and 15.

For the $\mathrm{KCl}$ medium we obtained $\mathrm{k}=4.1 \times 10^{-3} \mathrm{~cm}$. sec ${ }^{-1}$ which compared favorably with the one reported by earlier workers ${ }^{6}\left(k=4.0 \times 10^{-3} \mathrm{~cm} . \mathrm{sec}^{-1}\right)$ but the value, $\alpha=0.72$, was quite high, 1.e. more than twice the value reported hitherto. Similar observations abnormal values of were obtained by slotter ${ }^{11}$ in his study of streaming zinc amalgam electrode.

A value of $k=1.6 \times 10^{-2} \mathrm{~cm} . \mathrm{sec}^{-1}$, and $\alpha=0.54$ was obtained for this electrode reaction in KCNS medium. The earlier reported value was $\mathrm{k}=1.7 \times 10^{-2} \mathrm{~cm} \cdot \mathrm{sec}^{-1} .^{6}$

$11_{H}$. D. Slotter, "Kinetic Study at the Streaming Meroury Electrode", dissertation, University of Michigan, 1960; microfilm Mic 602058, Untversity Microrilms, Inc., Ann Arbor, Michigan. 
TABLE XII

Streaming amalgam electrode: $z$ inc in $I \mathrm{M}$ potassium chloride Exchange current density

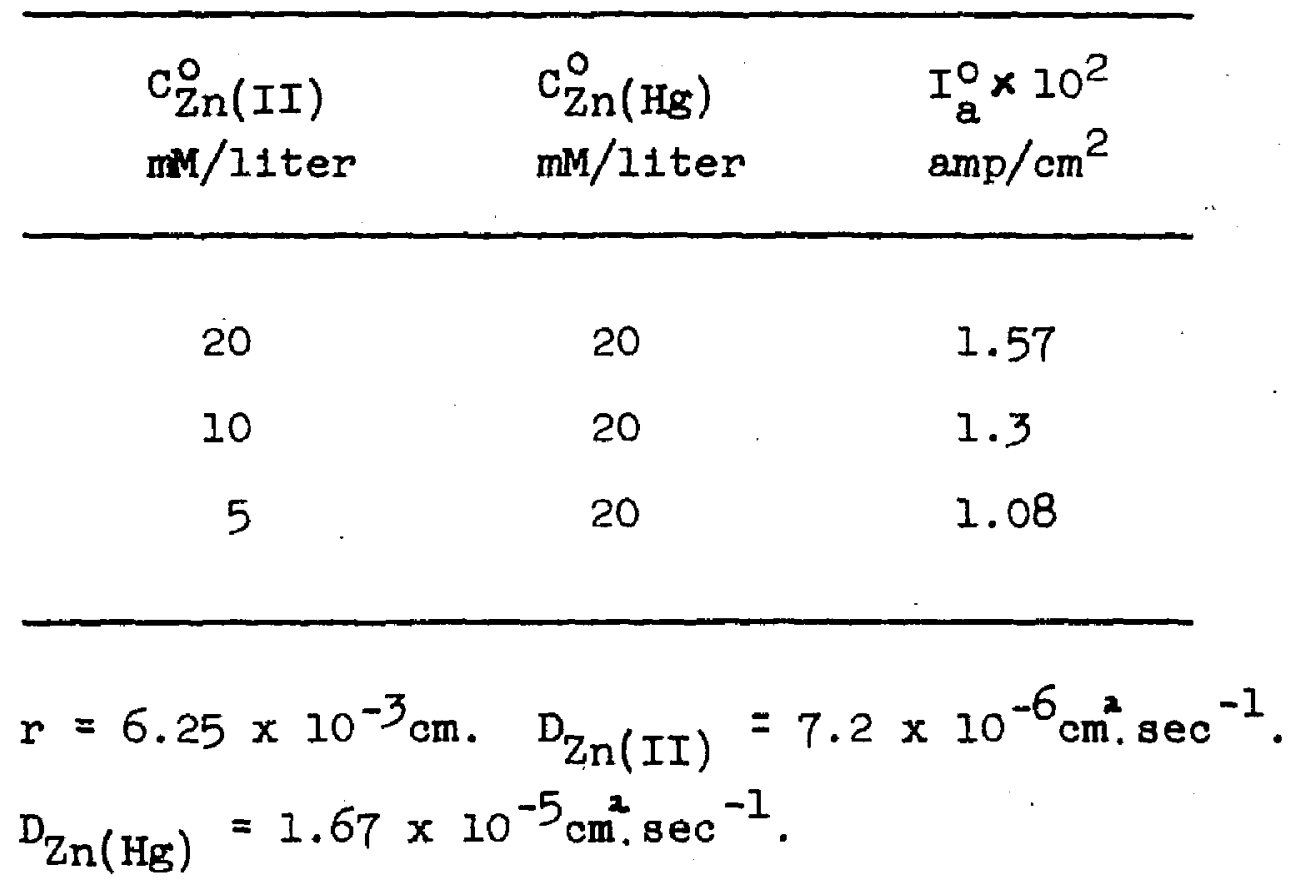




\section{TABLE XIII}

Streaming amalgam electrode: zinc in I M potassium thiocyanate - exchange current density

\begin{tabular}{ccc}
$\begin{array}{c}\mathrm{C}_{\mathrm{Zn}(I I)}^{\circ} \\
\mathrm{mM} / \text { IIter }\end{array}$ & $\begin{array}{c}\mathrm{C}_{\mathrm{Zn}(\mathrm{Hg})}^{\circ} \\
\mathrm{mM} / \text { Iiter }\end{array}$ & $\begin{array}{l}\mathrm{I}_{\mathrm{a}}^{0} \times 10^{2} \\
\mathrm{amp} / \mathrm{cm}^{2}\end{array}$ \\
\hline- & 20 & 3.77 \\
8 & 20 & 3.53 \\
4 & 20 & 2.29 \\
\hline
\end{tabular}

$$
\begin{gathered}
\mathrm{r}=6.25 \times 10^{-3} \mathrm{~cm} . \mathrm{D}_{\mathrm{Zn}(\mathrm{II})}=7.2 \times 10^{-6} \mathrm{~cm}^{2} \mathrm{sec}^{-1} . \\
\mathrm{D}_{\mathrm{Zn}(\mathrm{Hg})}=1.67 \times 10^{-5} \mathrm{~cm}^{2} \mathrm{sec}^{-1} .
\end{gathered}
$$




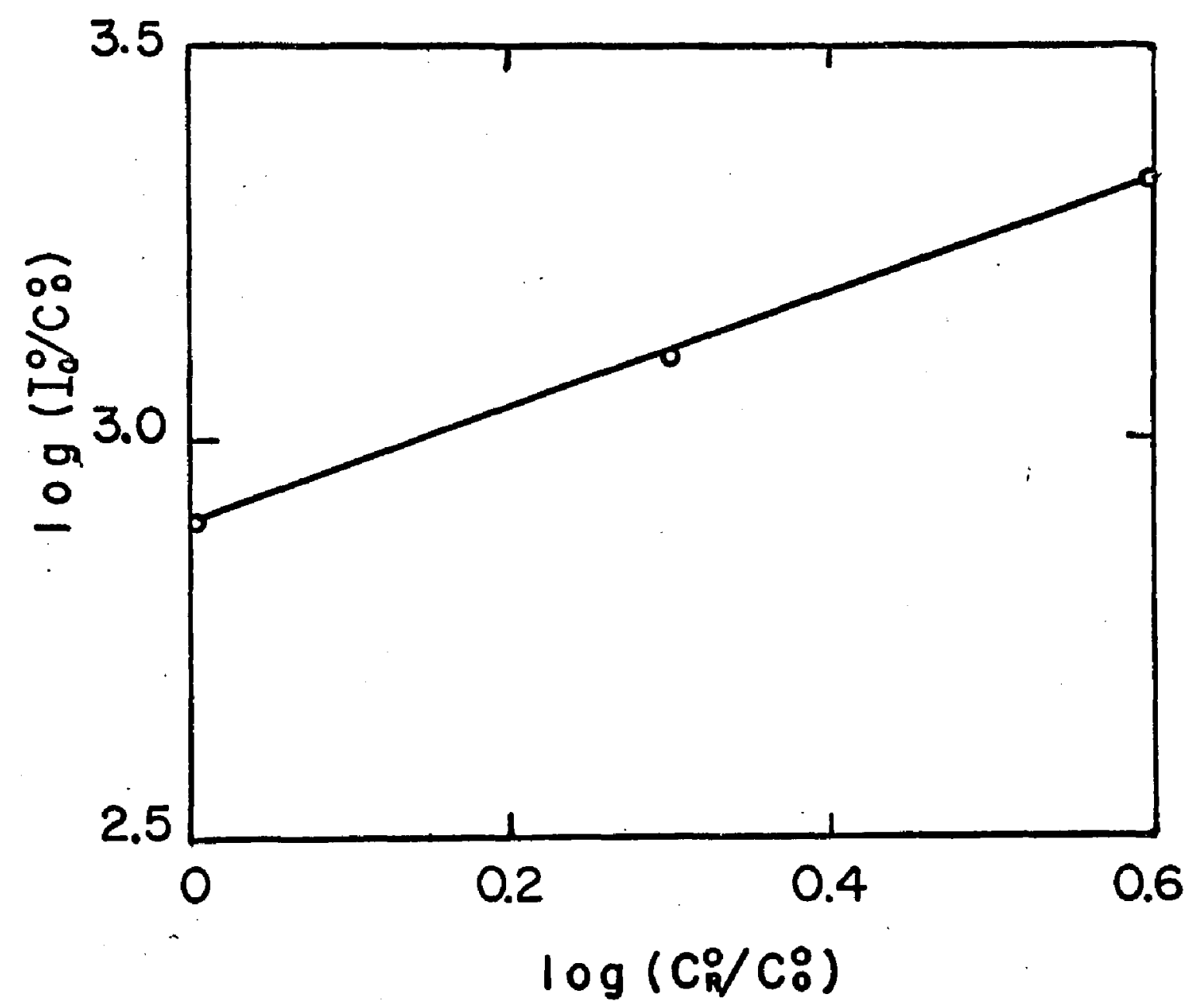

F18. 14 - Plot to determine the rate constant $k_{0}^{0}$ and the transfer coefficient $\alpha$ for $\mathrm{Zn}($ II $) / \mathrm{Zn}(\mathrm{Hg})$ in $1 \mathrm{M}$ potassium chloride. 


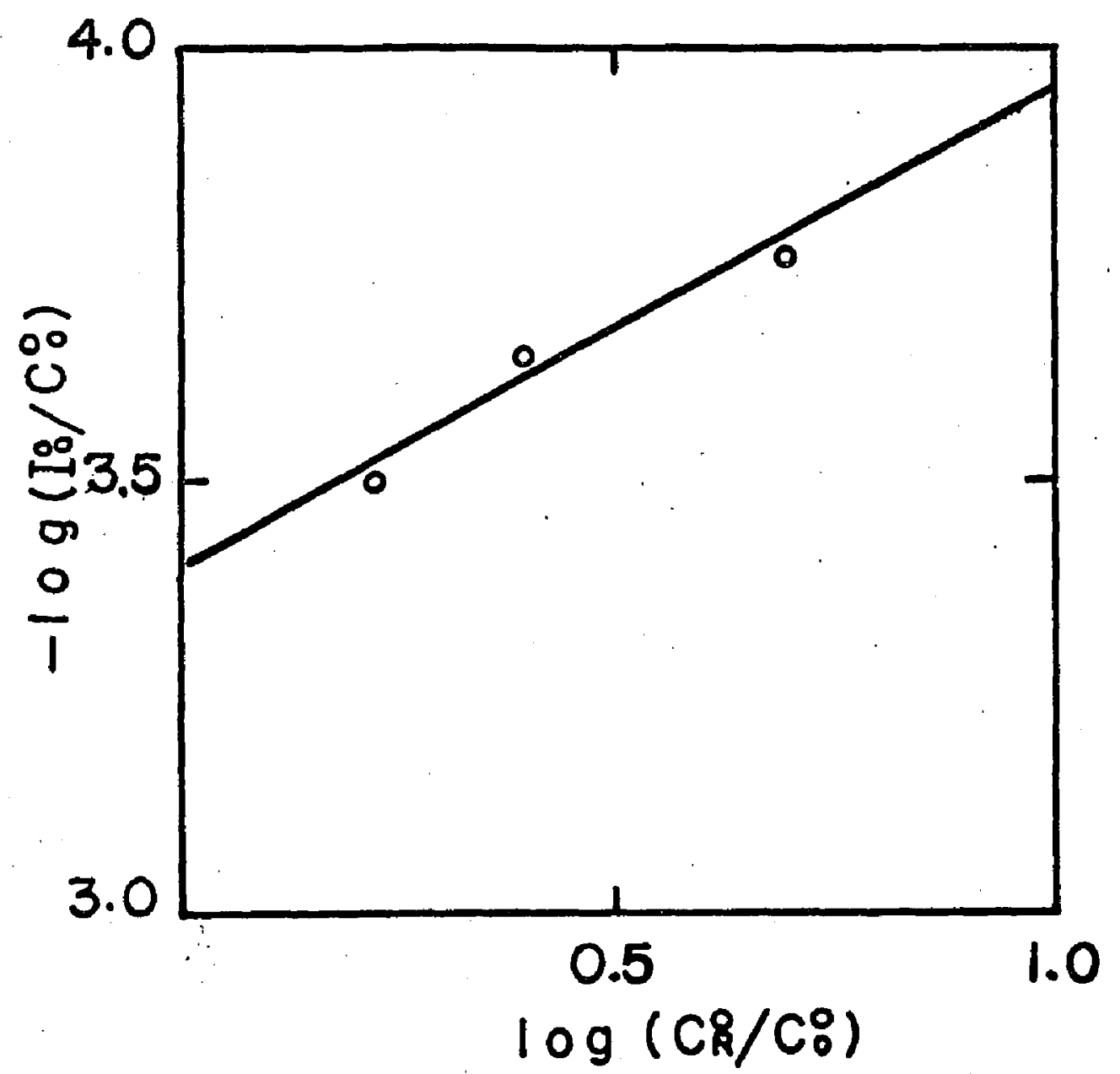

Fig. 15 - Plot to determine the rate constant $k_{0}^{0}$ and the transfer coefflcient $\alpha$ from the intercept and slope for $\mathrm{Zn}(\mathrm{II}) / \mathrm{Zn}(\mathrm{Hg})$ in $1 \mathrm{M}$ potassium thiocyanate. 
6) Mass Transfer Control by Diffusion and Migration The behavior of the electrode could be followed by this technique quite independently of the solution resistance. In this section the apparent diffusion coefficients for $\mathrm{Hg}(\mathrm{I})$ and $\mathrm{Hg}(\mathrm{II})$ ions were determined from experiments with the streaming mercury electrode in mercury salt solutions with and without supporting electrolyte. Sodium fluoride was used as the supporting electrolyte as it is known to be least adsorbed on the mercury-solution interface.

For very large overvoltages the general equation

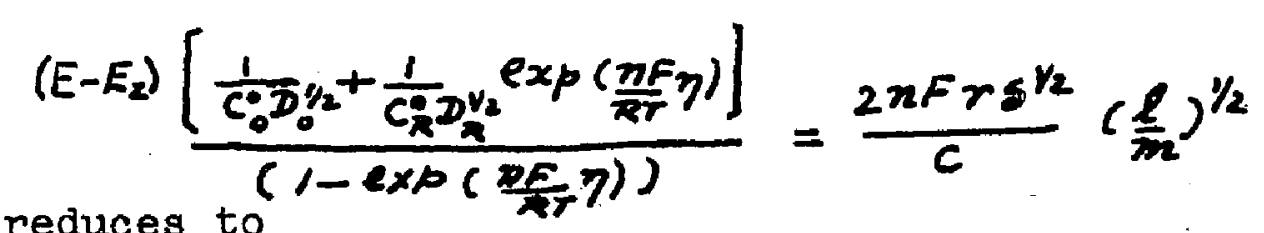

reduces to

$$
\left(E-E_{z}\right)=\frac{2 n F r S^{1 / 2} C_{0} D_{0}^{1 / 2}}{C}\left(\frac{l}{m}\right)^{1 / 2}
$$

for the reduction of mercury ions, which is purely mass transfer controlled. $\left(E-E_{z}\right)$ is written as $\left(E_{e}-E_{z}\right)+\eta$. If the variations of overpotentials are assumed not to affect the double-layer capacity very much in the range under study, then it is evident that the $\eta \mathrm{vs} .(1 / \mathrm{m})^{\frac{1}{2}}$ relationship should be linear with an intercept at $\left(E_{e}-E_{z}\right)$. The apparent diffusion coefficients could be calculated if all the other values are known. The concentrations of $\mathrm{Hg}(\mathrm{I})$ and $\mathrm{Hg}$ (II) studied were $0.21 \mathrm{mM}$ and $0.22 \mathrm{mM}$ respectively. As described 
In the legends of Figs. 16 and 17, the concentration of the supporting electrolyte was varied from $O M$ to $0.1 \mathrm{M}$. The capacity data were calculated from Russel's tables. 12

The $\eta$ vs. $(1 / m)^{\frac{1}{2}}$ plots for both mercuric and mercurous tons are shown in Figs. 16 and 17 . The validity of this relationship at all concentrations of the supporting electrolyte is strikingly demonstrated by the linear plots, all converging at the same intercept. The slope of the plot increases with the increase in the concentration of the supporting electrolyte, indicating the increase in diffusion rates. Table XIV gives the calculated apparent diffusion coefficients of $\mathrm{Hg}(I)$ and $\mathrm{Hg}(\mathrm{II})$ ions in different concentrations of supporting electrolyte.

The change in the value of the diffusion coefficlents might be attributed to the decrease in the value of transport number, with the increase in supporting electrolyte concnetration. It might be pointed out that in relation to the concentration ratio between the reducible ion and the supporting electrolyte, it is highly improbable that the multifold change in the

${ }^{12} \mathrm{C}$. D. Russel, "Charge and Outer Helmholtz Potential for a Mercury Electrode in Aqueous NaF at 25", J. Electroanal. Chem., 6, 486 (1963). 


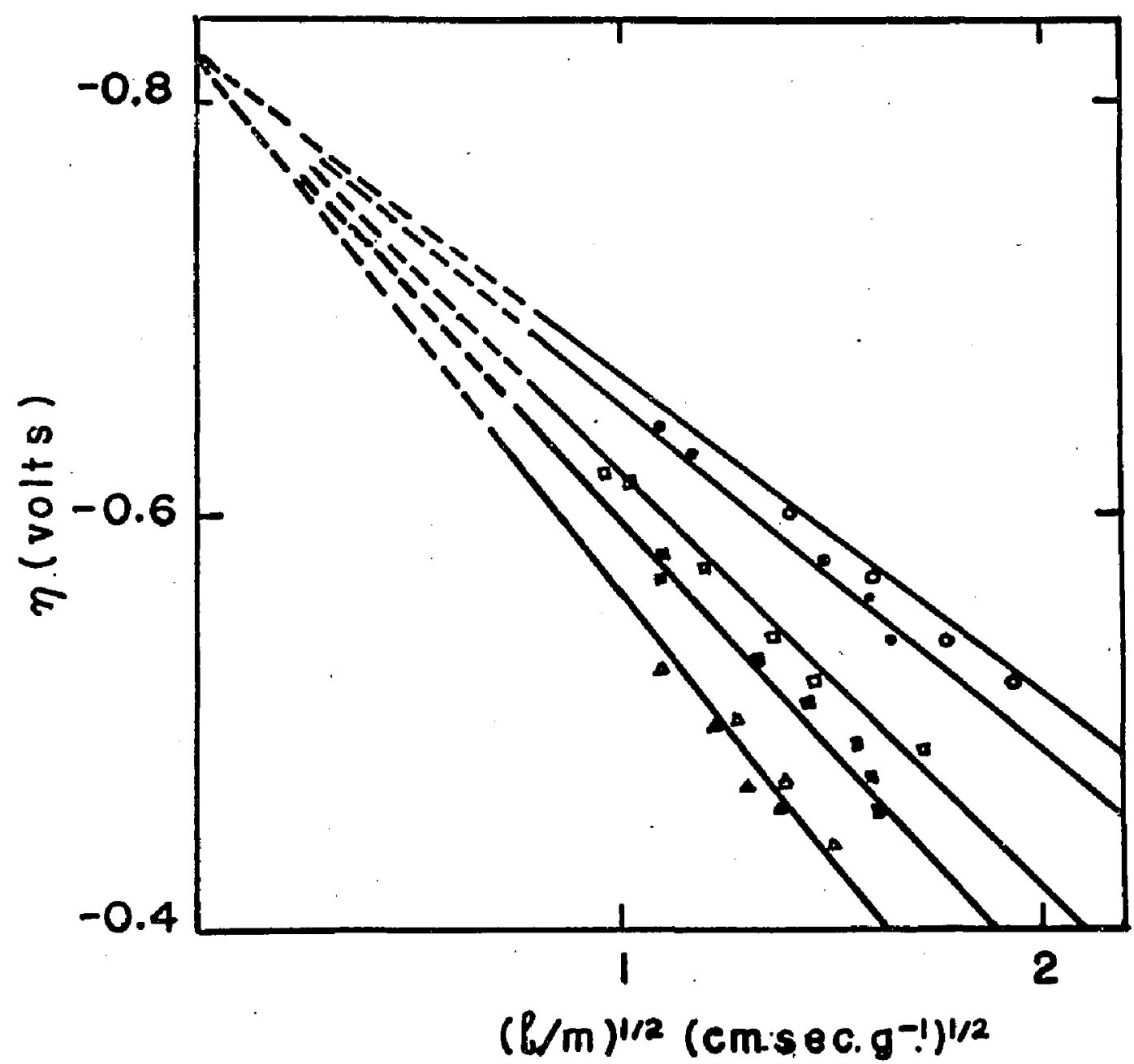

F1g. 16 - Mixed mass transfer control. Reduction of $0.22 \mathrm{mM} \mathrm{Hg}$ (II) in different concentrations of sodium fluoride as supporting electrolyte. $0, \bullet, \square$, and $\Delta$ correspond to $0,0.003$, $0.01,0.03$ and $0.1 \mathrm{M}$ sodium fluoride, respectively. 


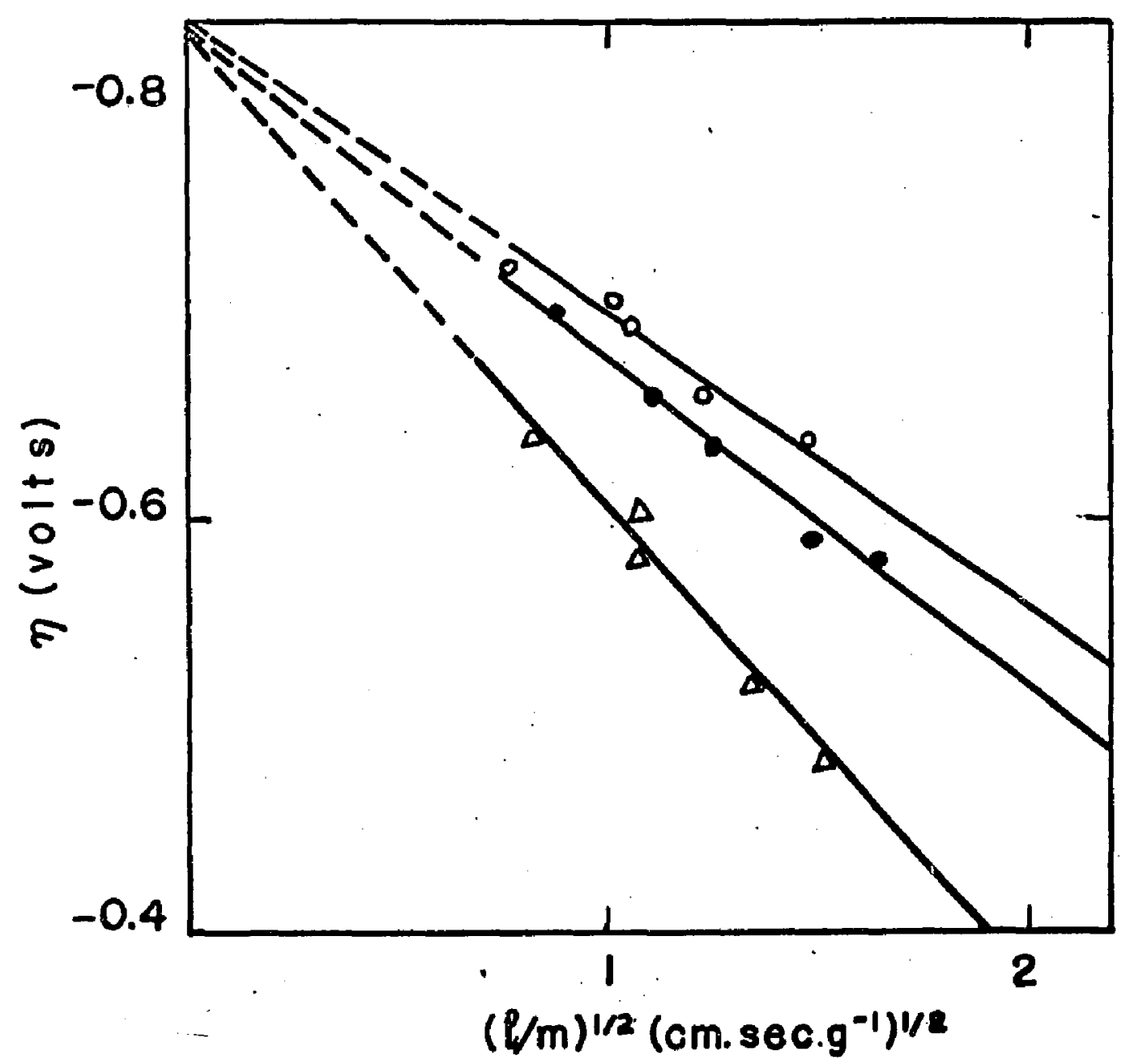

- Fig. 17 - Mixed mass transfer control - Reduction of $0.21 \mathrm{mM} \mathrm{Hg}(I)$ in different concentrations of sodium fluoride as supporting electrolyte. $0,-$, and $\Delta$ correspond to $0,0.01$ and $0.05 \mathrm{M}$ sodium fluoride respectively. 


\section{TABLE XIV}

Mixed masstransfer controlled: $\mathrm{Hg}$ (I) and $\mathrm{Hg}$ (II) in sodium f'lucride

\begin{tabular}{|c|c|c|c|}
\hline \multicolumn{2}{|c|}{$\begin{array}{l}\text { Concentration } \\
\text { of } \\
\text { sodium fluoride } \\
\text { moles/liter }\end{array}$} & \multirow{2}{*}{ 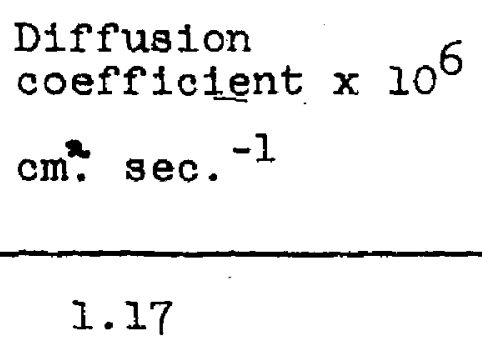 } & \multirow{2}{*}{$\frac{\begin{array}{c}\phi \\
\text { volts }\end{array}}{0.150 *}$} \\
\hline $\mathrm{Hg}$ (II) & 0 & & \\
\hline & 0.003 & 1.81 & 0.133 \\
\hline & 0.01 & 4.04 & 0.122 \\
\hline & 0.03 & 5.83 & 0.100 \\
\hline & 0.1 & 9.6 & 0.083 \\
\hline \multirow[t]{3}{*}{$\mathrm{Hg}(I)$} & 0 & 0.6 & $0.114 *$ \\
\hline & 0.01 & 2.3 & 0.098 \\
\hline & 0.05 & 7.4 & 0.08 \\
\hline
\end{tabular}

*The values for solutions without NaF were taken to be the same as that of $0.001 \mathrm{M} \mathrm{NaF}$. $r=6.25 \times 10^{-3} \mathrm{~cm}$. 
diffusion coefficient is due to the reduction in the transport value.

The stability constants for fluoride complexes of mercurtc and mercurous ions are reported as $k_{1}=10.7$ and $k_{1}=3.16$ respectively. ${ }^{13}$ Hence the effects due to complexation appear to be negligible. This point is further 1llustrated by the fact that all the plots for a given mercury ion concentration and different concentrations of sodium fluoride have the same intercept, indicating a constant $\mathrm{E}_{e}$.

In view of the above discussion, a possible correlation could be that of the $\phi$-effect, arising out of the electrical double layer. Since the whole process is taking place on the positive side of the electrocap1llary maximum, $\phi$ is positive and consequently positive mercury tons experience repulston in the potential gradient resulting in smaller apparent diffusion coefficients. The increase in the suporting electrolyte concentration decreases the $\boldsymbol{\phi}$-effect and the value of diffusion coefficient increases. In the table the approximate values of $\phi$ potentials are given for the median value of $\eta$. It should be noted, however,

$13 \mathrm{~J}$ : Bjerrum, G. Schwarzenbach, and L. G. Sillen, "Stability Constants of Metal Ion Complexes - Part II", The Chemical Soclety, London, 1958, p. 91. 
that the $\phi$-effect concerns only the double layer region whereas our experiments pertain to the much thicker diffusion layer. The $\phi$-values probably give a datum characterizing, in a way, the repulsion in the diffusion layer.

The values of $\mathrm{D}$ for $\mathrm{Hg}$ (II) and $\mathrm{Hg}(\mathrm{I})$ are reported as $8.2 \times 10^{-6} \mathrm{~cm}^{2} \cdot \mathrm{sec}^{-1}$ and $9.2 \times 10^{-6} \mathrm{~cm}^{2} . \mathrm{sec}^{-1}$ respectiveIy in $0.1 \mathrm{M}$ nitric acid. Our values are not too different from these, if one constders the variety of approximations made in calculating the values of $c_{1}$ and the slopes. 


\section{CHAPTER V}

\section{CONCLUSION}

The potential of the streaming (or amalgam) electrode at open circuit can be correlated to the kinetics and mass transfer characteristics of the process occurring on the electrode. Since measurements are carried out at open circuit, application to the study of electrode process in media of low conductivity (solvents of low dielectric constants) is concelvable. At least two difficulties would have to be considered in future studies of this type: interference resulting from the variations of potential along the jet and complication arising from migration. 


\section{APPENDIX ${ }^{1}$}

1. Derivation of Equation 2-22

$$
d 1 f=\frac{S d l}{\frac{1}{I_{a}^{0}}+N\left(\frac{l}{m}\right)^{1 / 2}}
$$

It is required to integrate from the tip of the capillary to the emerging length of the jet.

let $\frac{1}{I_{a}^{0}}+N\left(\frac{l}{m}\right)^{1 / 2}=y \quad$ therefore $l^{1 / 2}=\frac{m^{1 / 2}}{N}\left(y-\frac{1}{I_{a}^{0}}\right)$

then $\quad d y=\frac{1}{2} \frac{N}{(m l)^{y_{2}}} d l$

and

$$
d l=\frac{2(m \ell)^{1 / 2}}{N} \cdot d y
$$

therefore $d l=\frac{2 m}{N^{2}}\left(y-\frac{1}{I_{a}^{0}}\right) d y$

It follows $\int_{0}^{i_{f}} d i_{f}=\int_{0}^{l} \frac{S}{y} \frac{2 m}{N^{2}}\left(y-\frac{1}{I_{a}^{0}}\right) d y$

$$
i_{f}=\frac{25 m}{N^{2}}[y]_{0}^{l}-\frac{25 m}{N^{2} I_{a}^{l}}[\ln y]_{0}^{l}
$$

$i_{f}=\frac{2 S m}{N^{2}}\left\{N\left(\frac{\ell}{m}\right)^{1 / 2}-\frac{1}{I_{i}} \ln \left[1+N I_{a}^{*}\left(\frac{l}{m}\right)^{y_{2}}\right]\right\}$

$1_{\text {See P. Delahay, "Electrode Kinetics at Open }}$ Circuit at the Streaming Mercury Electrode. I. Theory", J. Electroanal. Chem., in press. 
76

$$
i_{f}=\frac{2 S m}{N^{2}} \frac{1}{I_{a}^{*}}\{\lambda-\ln (1+\lambda)\}
$$

$$
\left(\begin{array}{l}
A-6) \\
2-22
\end{array}\right)
$$

where

$$
\lambda=N \Gamma_{a}^{*}\left(\frac{l}{m}\right)^{y_{2}}
$$
2. Derivation of Equation 2-24 for Steady State

$$
\begin{aligned}
c\left(E-E_{2}\right) \frac{2 m}{r \delta} & =\frac{2 S m}{N}\left(\frac{l}{m}\right)^{1 / 2}\left[1-\frac{1}{\lambda} \ln (1+\lambda)\right] \\
\left(E-E_{2}\right) & =\frac{r \delta}{c} \frac{S}{N}\left(\frac{l}{m}\right)^{1 / 2}\left[1-\frac{1}{\lambda} \ln (1+\lambda)\right]
\end{aligned}
$$

substituting for $S$ and $N$

$$
\begin{aligned}
& S=2 \pi r\left[\exp \left(-\frac{\alpha n F}{\pi T} \eta\right)-\exp \left(\frac{(1-\alpha) n F}{\pi T}\right)\right.
\end{aligned}
$$

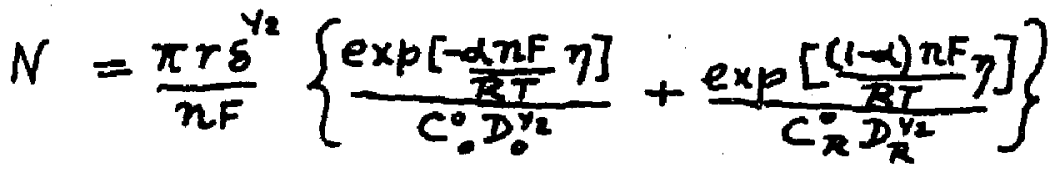

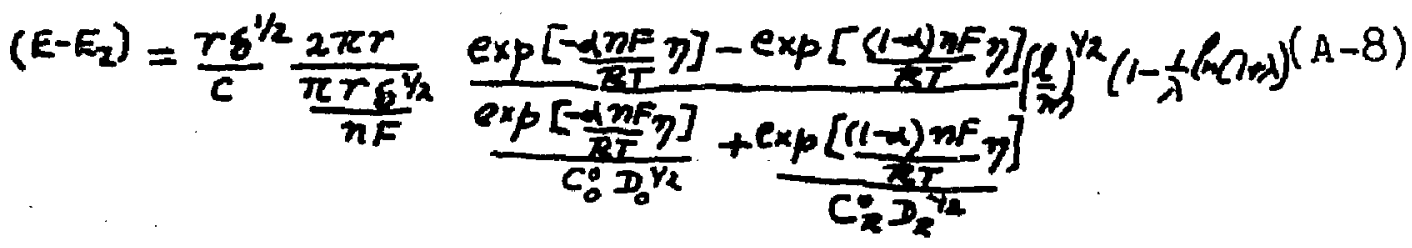

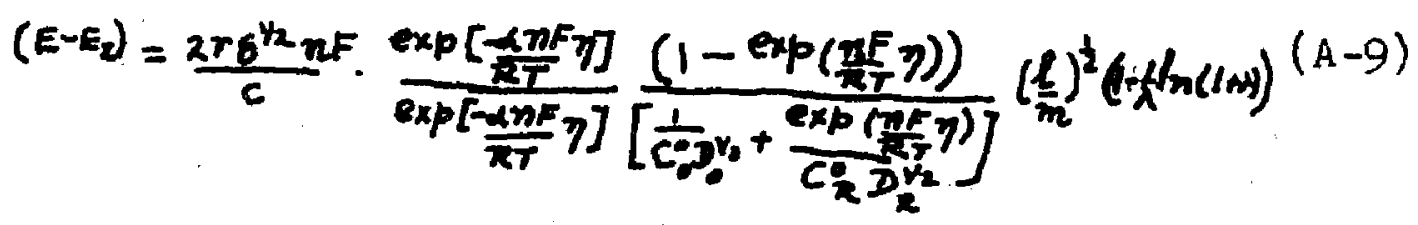

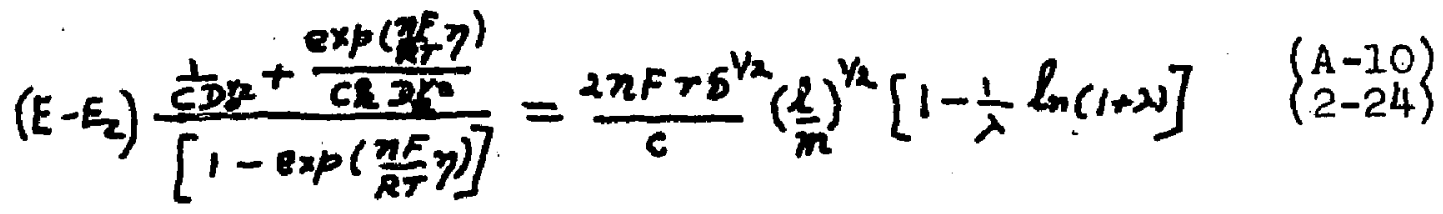


77

3. Derivation of Equation 2-35 for the SlopeIntercept Analysis:

The general equation 2-31 for small overvoltages

can be written as

$$
-\frac{1}{\eta}=\frac{Q}{P^{2}} \frac{r \delta}{C\left(E-E_{2}\right)} \frac{1}{I_{L}^{0}}(\lambda-\ln (1+\lambda)) \quad(A-I 1)
$$

where

$$
Q=2 \pi r \frac{n F}{\pi T}
$$

and

$$
P=\pi r^{2}\left(\frac{1}{C_{0}^{0} D_{0}^{Y_{2}}}+\frac{1}{C_{k}^{1} D_{R}^{Y_{2}}}\right)
$$

also

$$
\lambda=P I_{k}^{0}\left(\frac{l}{m}\right)^{Y_{2}}
$$

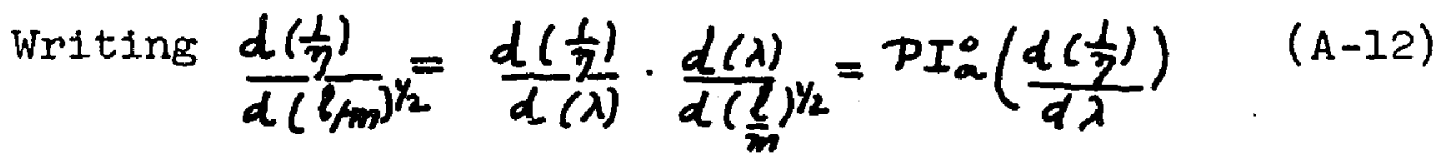

one gets from A-11

$$
\frac{d\left(\frac{1}{\eta}\right)}{d\left(\frac{2}{m}\right) Y_{2}}=-P I_{a}^{0} \frac{Q}{P^{2}} \frac{r \delta}{C\left(E-E_{2}\right)} \frac{1}{I_{2}^{*}}\left[1-\frac{1}{(1+\lambda)}\right]
$$

rearranging this

$$
\frac{d\left(\frac{1}{\eta}\right)}{d\left(\frac{l}{m}\right)^{y_{2}}}=-\frac{Q}{P} \frac{r \delta}{C\left(E-E_{2}\right)} \frac{\lambda}{(1+\lambda)}
$$

or

$$
\frac{d\left(\frac{L}{m}\right)^{1 / 2}}{d\left(\frac{1}{\eta}\right)}=-\frac{P}{Q} \frac{c\left(E-E_{z}\right)}{r \delta}\left(1+\frac{1}{\lambda}\right)
$$

$(A-15)$

substituting for $\lambda$,

$$
\frac{d\left(\frac{R}{m}\right)^{1 / 2}}{d\left(\frac{1}{\eta}\right)}=-\frac{P}{Q} \frac{c\left(E-E_{2}\right)}{r S}\left[1+\frac{1}{P I_{Q}}(m / l)^{1 / 2}\right]
$$$$
\left(\begin{array}{l}
A-16 \\
2-35
\end{array}\right)
$$ 


\section{SELECTED BIBLIOGRAPHY}

Delahay, P. "Double Layer and Electrode Kinetics", Intersolence - Wiley, New York, in press.

Delahay, P. "Fundamentals of Coulostat1c Analysis", Ana 1. Chem., 34, 1267 (1962).

Delahay, P. "Electrode Kinetics at Open Circuit at the Streaming Mercury Electrode", J. Electroanal. Chem., In press.

Grahame;"D. C. "The Electrical Double Layer and the Theory of Electrocapillarity", Chem. Rev., 41 , $441(1947)$.

Heyrovsky, J and Forjet, "Oszillographische Polarographie", Z. Physik. Chem., 193, 83 (1943)

Koryta, J. "Diffusion and Kinetic Currents at the Streaming Mercury Electrode", Coll. Czechoslov. Chem. Communs., 19, 433 (1954)

Lingane, J. "Polarographic Characteristics of Vanadium in Its Various Oxidation States", J. Am. Chem. Soc., 67, 182 (1945).

Randles, J. E. B. and Sommerton, K. W. "The Determination of Kinetic Parameters of Redox Reactions from Current Potential Curves", Can. J. Chem., 37, 238 (1959).

Randles, J. E. B. and Sommerton, K. W. "Kinetics of Rapid Electrode Reactions", Trans. Faraday Soc., 48, 937 (1952).

Schofield, R. K. "Verification of Gibbs' Adsorption. Equation", Phil. Mag., (7), 1, 641 (1926).

Slotter, H. D. "Kinetic Study at the Streaming Mercury Electrode", dissertation, University of Michigan, 1960; microfilm Mic 602058, University Microfilms, Inc.; Ann Arbor, Michigan. 
Sluyters-Rehbach, M. and Sluyters, J. H. "The Differential Capacity of the Mercury-1 $\mathrm{M} \mathrm{HClO}_{4}$ Solutions Interface at High D.C.Potentials", Rec. trav. Chim., 83, 217 (1964).

Spear, C. D. "Transient Electrode Potentials of Mercury", dissertation, University of Utah, 1960; University Microfilms Inc.; Ann Arbor, Michigan.

Valenta, P. "Studium der an der strömenden Quecksilberelektrode auftretenden Stromdiskontinuität", Coll. Czechoslov. Chem. Communs., 16, 239 (1951).

Watanabe, A. "A.C.Methods in Interfacial Electrical Phenomenon", J. Electrochem. Soc., 110, 72 (1963). 
VITA

Vakula Sampathkumar Srinivasan was born March 25, 1936 In Madras, India. He recelved there his primary and secondary education. He matriculated from Ramakrishna Mission High School in 1951.

He attended Ioyola College, University of Madras from 1951 until 1956 when he graduated with the Honors degree in chemistry.

In 1957 he worked as a Chemical Assistant, for the Archaeological Department, Government of India, at the Ajantha and Ellora caves. During 1957-58 he was selected for the Training School of the Atomic Energy Eatabl1shment Trombay, Ind1a. In 1958 he received his honorary M.A., from the University of Madras. From 1958 to 1961 he worked as a scientist, at the Analytical Division, Atomic Energy Establishment Trombay, India. He entered the Graduate School at Loulalana S̄tate University in 1961. He is a member of Phi Lambda Upsilon. Now he 18 a candidate for the degree of Doctor of Philosophy. 


\section{EXAMINATION AND THESIS RHPORT}

Candidate: Vakula s. Srinivasan

Major Field: Chemistry

Title of Thesis: Electrode Kinetics at Open Circuit at the Streaming Mercury Electrode

Approved:

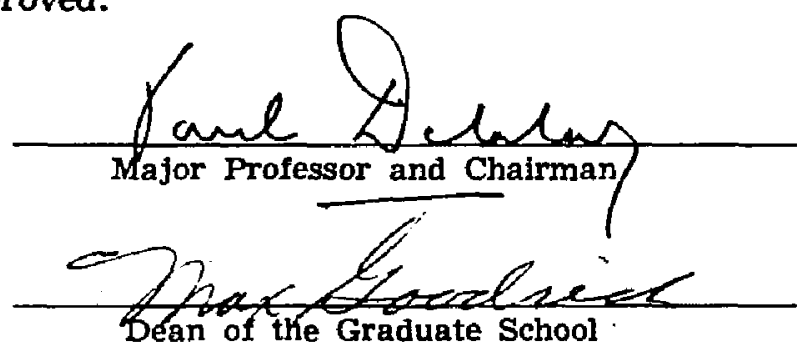

EXAMINING COMIMITTEE:
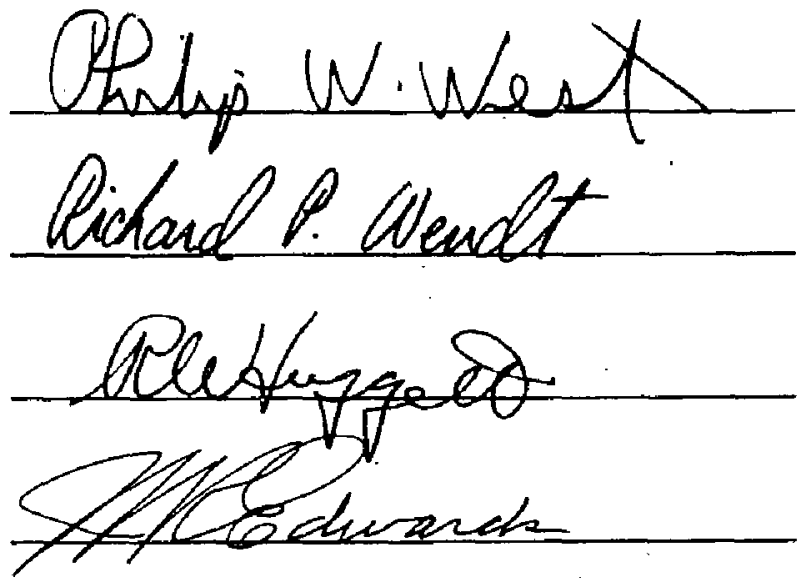

Date of Examination: 